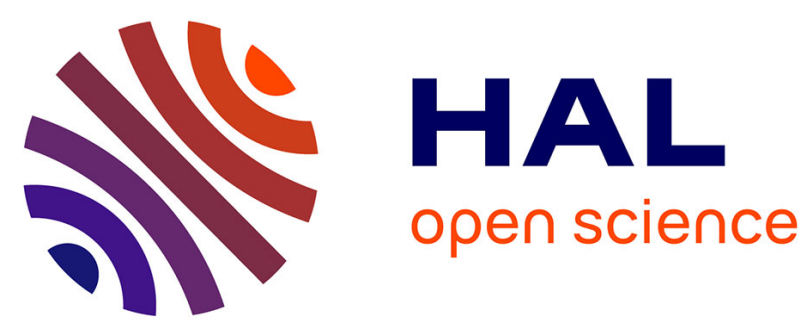

\title{
Ex vivo detection and quantification of gold nanoparticles in human seminal and follicular fluids
} Dimitrios Bitounis, Jean-Philippe Klein, Lionel Maurice Edouard Mery, Amira El Merhie, Valérie Forest, Delphine Boudard, Jérémie Pourchez, Michèle Cottier

\section{To cite this version:}

Dimitrios Bitounis, Jean-Philippe Klein, Lionel Maurice Edouard Mery, Amira El Merhie, Valérie Forest, et al.. Ex vivo detection and quantification of gold nanoparticles in human seminal and follicular fluids. Analyst, 2018, 143 (2), pp.475 - 486. 10.1039/c7an01641g . hal-01896549

\section{HAL Id: hal-01896549 \\ https://hal.science/hal-01896549}

Submitted on 16 Oct 2018

HAL is a multi-disciplinary open access archive for the deposit and dissemination of scientific research documents, whether they are published or not. The documents may come from teaching and research institutions in France or abroad, or from public or private research centers.
L'archive ouverte pluridisciplinaire $\mathbf{H A L}$, est destinée au dépôt et à la diffusion de documents scientifiques de niveau recherche, publiés ou non, émanant des établissements d'enseignement et de recherche français ou étrangers, des laboratoires publics ou privés. 


\section{Ex vivo detection and quantification of gold nanoparticles in human seminal and follicular fluids}

Dimitrios Bitounis $^{\mathrm{a}}$, Jean-Philippe Klein ${ }^{\mathrm{a}, \mathrm{b}}$, Lionel Mery ${ }^{\mathrm{b}}$, Amira El-Merhie ${ }^{\mathrm{c}}$, Valérie Forest ${ }^{\mathrm{c}, \mathrm{d}, \mathrm{e}}$, Delphine Boudard ${ }^{\mathrm{a}, \mathrm{f}}$, Jérémie Pourchez ${ }^{\mathrm{c}, \mathrm{d}, \mathrm{e}}$ and Michèle Cottier ${ }^{\mathrm{a}, \mathrm{f}}$

a Université de Lyon, Faculté de Médecine, INSERM U1059 SAINBIOSE, F-42270 SaintEtienne, France. E-mail: dimitrios.bitounis@univ-st-etienne.fr

${ }^{\mathrm{b}}$ CHU Saint-Etienne, UF 6726 Laboratoire de Biologie de la Reproduction, F-42055 SaintEtienne, France

${ }^{\mathrm{c}}$ Ecole Nationale Supérieure des Mines de Saint-Etienne, CIS-EMSE, SAINBIOSE, F-42023 Saint Etienne, France

${ }^{\mathrm{d}}$ INSERM, U1059, F-42023 Saint-Etienne, France

${ }^{\mathrm{e}}$ Université de Lyon, F-69000 Lyon, France

${ }^{f}$ CHU de Saint-Etienne, UF 6725 Laboratoire de Cytologie et Histologie Rénale, F-42055 Saint-Etienne, France 


\begin{abstract}
Increasing consumption of engineered nanoparticles and occupational exposure to novel, ultrafine airborne particles during the last decades has coincided with deterioration of sperm parameters and delayed fecundity. In order to prevent possible adverse health effects and ensure a sustainable growth for the nanoparticle industry, the ability to investigate the nanosized, mineralogical load of human reproductive systems is becoming a real clinical need. Toward this goal, the current study proposes two methods for the detection and quantification of engineered nanoparticles in human follicular and seminal fluid, developed with the use of welldefined $60 \mathrm{~nm}$ Au particles. Despite the complexity of these biological fluids, simple physical and chemical treatments allow for the precise quantification of more than 50 and $70 \%$ wt of the spiked Au nanoparticles at low $\mu \mathrm{g} \mathrm{ml}^{-1}$ levels in follicular and seminal fluids, respectively. The use of electron microscopy for the detailed observation of the detected analytes is also enabled. The proposed method is applied on a small patient cohort in order to demonstrate its clinical applicability by exploring the differences in the metal and particulate content between patients with normal and low sperm count.
\end{abstract}




\section{Introduction}

The recent integration of nanotechnologies in various industrial fields (e.g., food industry, cosmetics, medicine) has allowed for the interactions of the general public with a variety of nanomaterials and has led to increased occupational exposure to engineered nanoparticles. ${ }^{1}$ The ability of nanosized objects to cross human physiological barriers has already been confirmed ${ }^{2}$ and a relevant toxicological question is whether an ensued system-wide distribution of these pollutants may impose long-term repercussions on male and female reproductive system.

Several studies have reported a gradual decline in sperm count for industrialised countries ${ }^{3}$ over the last century while a meta-analysis has recently confirmed this alarming trend. ${ }^{4}$ This decline is most likely due to environmental factors and while some risk factors for poor sperm quality have already been identified (e.g., pesticides, smoking tobacco), others might still remain undiscovered. In vitro studies have already pointed to the toxic effect of nanoparticles on germinal cells. Braydich-Stolle et al. showed that $15 \mathrm{~nm} \mathrm{Ag}$ particles over a certain concentration $\left(>10 \mu \mathrm{g} \mathrm{ml}^{-1}\right.$ ) are able to enter spermatogonial stem cells, impair mitochondrial function, cause LDH leakage, reduce cell proliferation through reduction of signal transduction from glial cell-derived neurotrophic factor and slightly increase apoptosis. ${ }^{5}$ These effects were more pronounced after exposure to small nanoparticulate matter rather than to ionic silver or the larger Ag particles employed in the study $(80 \mathrm{~nm}) .{ }^{6}$ Also, the $15 \mathrm{~nm}$ sized Ag nanoparticles tended to be more toxic than $30 \mathrm{~nm} \mathrm{MoO}_{3}$ or $\mathrm{Al}$ ones, suggesting that their composition might also be a determining factor. Asare et al. showed that human testicular embryonic carcinoma cells and primary mice testicular cells underwent necrosis upon exposure to $20 \mathrm{~nm} \mathrm{Ag}$ particles at $10 \mu \mathrm{g} \mathrm{ml}^{-1}$, whereas $21 \mathrm{~nm} \mathrm{TiO}_{2}$ particles tended to increase the proliferation of testicular cells in mice. ${ }^{7}$ Other animal model studies have suggested that nanoparticles may negatively impact spermatogenesis: a single intravenous injection of $5 \mathrm{mg} \mathrm{kg}^{-1}$ of $20 \mathrm{~nm} \mathrm{Ag}$ particles in rats caused a slight decrease in epididymal sperm count 8 and daily inhalation of $0.1 \mathrm{mg}$ carbon black nanoparticles (14-95 nm) for seven days significantly reduced daily sperm production in mice. ${ }^{9}$ In a study that investigated the effect of wear debris from metal-on-metal prostheses on male fertility, Wang et al. found that intra-articular injection of a mixture of CoCr submicronand nano-sized particles above $500 \mathrm{mg} \mathrm{kg}^{-1}$ per week for 10 weeks could reduce epididymal sperm count in rats. ${ }^{10}$ Finally, some studies have observed only transitory effect of nanoparticles on spermatogenesis, like $\mathrm{Xu}$ et al. who found that $64 \mathrm{~nm} \mathrm{SiO} 2$ particles intravenously injected at $20 \mathrm{mg} \mathrm{kg}^{-1}$ every 3 days for 13 days in mice could reversibly impair spermatogenesis for about a whole spermatogenesis period. ${ }^{11}$ 
A recent study has shown increase in female-indexed infertility for parts of Africa and Asia. ${ }^{12}$ When it comes to the effect of environmental factors, it has been shown that the blood-ovary barrier can be compromised by asbestos fibres following chronic exposure ${ }^{13}$ and their presence has been significantly associated with increased risk for ovarian cancer. ${ }^{14}$ However, there are only few studies on the biodistribution and toxicological effects of nanoparticles on mammalian ovaries and follicles (the structure that protects and nourishes the maturing oocyte). An in vitro study by Stelzer et al. showed that $10 \mathrm{~nm}$ Au particles are internalised by rat granulosa cells ${ }^{15}$ while Preaubert et al. correlated the internalisation of agglomerates of $3 \mathrm{~nm} \mathrm{CeO}_{2}$ particles in mouse follicular cells ex vivo with significant DNA damage in oocytes. ${ }^{16}$ A recent in vivo work by Tassinari et al. demonstrated the dose-dependent cytotoxic effect of $25 \mathrm{~nm}$ anatase $\mathrm{TiO}_{2}$ particles on the same type of cells, although the particles themselves were not imaged. ${ }^{17}$ As revealed by an ex vivo study on rat ovaries, nanoparticles can still exert noxious effects by disrupting the secretion and bioavailability of endocrine molecules even if they do not physically interact with the oocyte as just tens of particles of $10 \mathrm{~nm}$ Au particles were capable of significantly altering the biosynthesis of steroid hormones. ${ }^{18}$

The available literature suggests that nanoparticles have the potential to jeopardise the normal function of the male and female reproductive system. Despite these alarming signs, there are no clinical studies to explore the potential risk in fertility and fecundity posed by human exposure to engineered nanoparticles. This literature gap permits the rampant speculation around the hazard posed by nanoparticles, which could impede the commercialisation of nanotechnology-enabled products and services. This is why we contend that human-centric research is crucial, but a limiting factor is the absence of biological markers following the exposure of an organism to nanoparticles. Therefore, there needs to be a clinically oriented method for assessing the nanoparticulate load of complex, human biological fluids. We have elsewhere described how analyzing nanoparticles in human biological milieu is a daunting task, especially when the analytes are of unknown nature and/or abundance. ${ }^{19}$

The aim of the current study was to design methods for the detection and quantification of nanoparticles in human follicular and seminal fluid (FF and SF, respectively). The methods are based on recommendations made by ASTM International ${ }^{20}$ and the International Standards Organization for the ex vivo treatment of biological fluids that contain exogenous particles. ${ }^{21}$ Another resource was a comprehensive review on the detection of nanomaterials in complex matrices by von der Kammer et al. ${ }^{22}$ In short, we employed a combination of physical (sonication, single-step gradient centrifugations) and chemical (dispersion buffer, oxidant) 
treatments in order to isolate small quantities of $60 \mathrm{~nm} \mathrm{Au}$ particles that had been previously added in SF and FF.

Au nanoparticles were used as analytes as their properties are well-established and can be easily characterised by ensemble and nanoscale analytical techniques. The method was evaluated by routine biochemical assays and the application of dynamic light scattering (DLS), fieldemission scanning electron microscopy (FESEM), transmission electron microscopy (TEM) and inductively-coupled optical emission spectroscopy (ICP-OES). The developed method was applied on a small cohort of male patients in order to assess the mineralogical differences between patients with normal and low sperm count, based on the threshold value of $>39 \times 10^{6}$ cells per ejaculate. The same, immediate sorting of female patients to "normal" and "abnormal" groups is not possible based on a single parameter. Within the available timeframe, we did not have enough clinical data to categorise the female patients, therefore the developed method of particle extraction from FF was not applied on a patient cohort.

\section{Results and discussion}

\subsection{Au nanoparticles, $F F$, and $S F$}

The stock dispersion of citrate-capped $\mathrm{Au}$ nanoparticles (AuNP) with a calculated mass concentration of $\approx 40.0 \mu \mathrm{g} \mathrm{ml}^{-1}$ had a purple colour due to the surface plasmon resonance effect in colloids in this size range. The particles' colloidal stability in deionised water at $4.0 \mu \mathrm{g} \mathrm{ml}^{-1}$ was measured by DLS: mean hydrodynamic diameter was $74.8 \pm 0.2 \mathrm{~nm}$ (Fig. 1A) with a dispersity index of $0.157 \pm 0.010$, indicating a rather narrowly distributed size population; zeta potential was $-44.3 \pm 0.2 \mathrm{mV}$, an indication of excellent dispersibility. FESEM images showed particles of an angular shape and multi-faceted morphology which are typical characteristics for AuNP (Fig. 1B).

Pooled SF and FF which were used for the development of the methods are presented in Fig. 1C. Sperm cell concentration in SFs from 20 healthy patients, i.e., with normal sperm parameters, was $24 \times 106$ cells per $\mathrm{ml}$ and total protein concentration of its plasma was 9.953 $\mathrm{mg} \mathrm{ml}^{-1}$. Total protein concentration of FF from patients undergoing in vitro fertilization $(\mathrm{n}=$ 20) was upwards of $40 \mathrm{mg} \mathrm{ml}^{-1}$ and its red tint was due to small quantities of blood aspirated during oocyte pick-up.

\subsection{Ex vivo treatment of FF spiked with AuNP}

\subsubsection{Addition of dispersion buffer.}


Freezing and thawing cycles of aqueous protein solutions have shown to cause significant protein denaturation ${ }^{23}$ and are thus suspected to create structures able to entrap nanoparticles by non-specific interactions. In this study, because of the highly concentrated biomolecular content of FF, it was considered that protein flocculation could impede particle sedimentation under mild centrifugal forces. Also, varying amounts of blood frequently pollute the FF and could interfere with analytical techniques like DLS and ICP-OES. Therefore, a cell lysis and protein dispersion buffer (CPD) was added to FF in order to de-agglomerate and lyse any denatured protein clusters and cells, respectively.

When compared to phosphate-buffered saline (PBS), CPD provided an 8-fold increase in the ability of protein molecules to cross a filter with a molecular weight cut-off (MWCO) at 100 $\mathrm{kDa}$, suggesting that proteins in FF had indeed undergone severe clumping during storage. The hydrodynamic size of AuNP at $4.0 \mu \mathrm{g} \mathrm{ml}^{-1}$ in the presence of increasing FF volume ratios as well as the effect of CPD were also studied. First, it was seen that gradual increase in FF concentration was followed by an increase in the normalised count rate of scattered photons (dkcps) (Fig. 2A, closed circles). Broadening of the peak of AuNP with an eventual appearance of a peak at $30 \mathrm{~nm}$ in the intensity-weighted size distribution was also observed (Fig. 2B). Expectedly, the dilution by CPD decreased the dkcps signal, but increasing concentrations of FF returned initially diminishing dkcps (Fig. 2A, open circles). This may be attributed to the formation of surfactant-based micelles which disappeared upon their interaction with the components of FF. The surfactant action of CPD is expected to change the conformation of biomolecules from a globular to a linear one as well as de-agglomerate any denatured protein clusters. Still, after a certain volume ratio, the ability of CPD to disperse the FF components is saturated and dkcps signal increases again.

\subsubsection{Single-step centrifugation for the extraction of AuNP from $F F$.}

The CPD-treated FF was placed on top of a glycerol solution in which AuNP migrated with the help of centrifugation. Because glycerol is hygroscopic, it slowly mixes with FF. However, their stark colour difference provided an optical cue as to where to puncture the tubes and successfully separate FF from the glycerol fraction with the extracted AuNP after the centrifugation.

\subsubsection{Quantification of AuNP extracted from FF.}

A matrix-matched calibration curve showed that it was possible to detect and confidently $\left(\mathrm{r}^{2}=\right.$ 0.999) measure AuNP by ICP-OES once extracted from FF in glycerol-rich samples and after 
their dilution in deionized water. Particle quantification is possible without prior acid digestion of the sample, as has been shown Pace et al., assuming a homogeneous and stable particle dispersion. ${ }^{24} \mathrm{~A}$ linear relationship between known amounts of AuNP and light intensity was thus used to quantify AuNP extracted from FF spiked at concentrations between 1.0 and $8.0 \mu \mathrm{g}$ $\mathrm{ml}^{-1}$ (Fig. 3A): the extraction yield was calculated at 29 and 55\% from $1000 \mu \mathrm{lF}$ aliquots spiked at 2.0 and $4.0 \mu \mathrm{g} \mathrm{ml}^{-1}$ of AuNP, respectively. More details on the preparation of the calibration curve can be found in Fig. 2 of Supplementary Information. Particles extracted from FF aliquots spiked with AuNP at $1.0 \mu \mathrm{g} \mathrm{ml}^{-1}$ were not detectable due to the unusually high baseline of Au signal in the matrix, an artefact attributable to the high organic content of the samples.

\subsubsection{Characterisation of AuNP before and after extraction from FF.}

Direct DLS observation of AuNP in FF was suboptimal because of the biomolecular contents of the sample. FF contains particles of small molecular weight with a geometric diameter of up to a few nanometres, ${ }^{25}$ but storage conditions can progressively cause flocculations that measure up to a few hundred nanometres in hydrodynamic diameter. Even more so, small amounts of granulosa, theca, and blood cells aspirated during oocyte pick-up might generate misleading dkcps signals. The excellent scattering ability of AuNP at $4.0 \mu \mathrm{g} \mathrm{ml}^{-1}$ did generate a shoulder on the main peak of FF (Fig. 3B), but it was smothered by elevated levels of biological noise. After their extraction in the glycerol cushion, accurate DLS measurements require the estimation of sample viscosity. This was possible by calculating the remaining glycerol volume after the aspiration of FF. DLS revealed a particle distribution with a z-average at $153 \mathrm{~nm}$ which, compared to that of AuNP in PBS (100 nm), indicated a considerable shift to larger sizes, probably due to particle agglomeration and adsorption of biomolecules on their surface (Fig. 3B). Contrary to ICP-OES, AuNP could be detected by DLS after their extraction from FF spiked at concentrations as low as $1.0 \mu \mathrm{g} \mathrm{ml}^{-1}$. The dkcps signal from extracted particles significantly increased at each concentration step and was stronger than the negative sample (FF alone) (Fig. 3C). Generally, reasons for incomplete particle extraction could be the partial migration of AuNP to the glycerol-based compartment or the exclusion of otherwise extracted particles from the ICP-OES nebuliser due to agglomeration. The absence of agglomerates as well as the linear relationship between the AuNP concentrations in spiked FF samples and their respective dkcps signals obtained from extracted AuNP (rs = 0.991) suggested that the extraction procedure has a good extraction yield. Therefore, the discrepancy between 
the quantitative data by ICP-OES and the semi-quantitative evaluation of DLS point to a problematic quantification by the former which demands further investigation.

Direct TEM observations of FF are possible without any treatment and can reveal native proteoglycans which appear as globular particles of up to $\approx 30 \mathrm{~nm}$ in diameter. In this work, nano-sized bodies were visible without any prior treatment (Fig. 4A), however, image quality suffered as the carbon-rich sample dimmed the brightness and suppressed spatial resolution. In comparison, application of the currently proposed treatment returned a relatively clean substrate (Fig. 4B) and allowed for the detailed observation of extracted AuNP which appeared with a rougher morphology and occasionally increased geometric diameter (Fig. 4C). An additional image of the extracted AuNP and a frequency distribution of their geometric diameters is available in Fig. 1 of Supplementary Information. Based on the propensity of uncoated AuNP to adsorb protein molecules when found in biological media, ${ }^{26}$ it can be assumed that the change in their geometric diameter could be due to the biomolecular content of FF.

\subsection{Ex vivo treatment of SF for the recovery of AuNP}

In contrast with the procedure followed for FF (where AuNP were extracted from the bulk volume of the biological sample), the procedure for SF was inverted with the biological content of semen being progressively removed from the sample. Because of the elevated viscosity and high cellular content of SF, the method required multiple steps. Initially, a mild centrifugation was employed to remove spermatozoa which are naturally well-dispersed in seminal plasma and readily sediment due to their large size. Next, $\mathrm{H}_{2} \mathrm{O}_{2}$ was used to oxidise the lipidic content of $\mathrm{SF}^{27}$ and phospholipids in the plasma membrane of any cells that were not successfully removed during the first centrifugation. Finally, the version of CPD buffer for the dispersion of SF components lacked urea and thiourea because most of the protein content was removed by aspiration. After treatment, $99.7 \%$ of the total protein content of seminal plasma is discarded and sperm cell concentration is reduced by $87.5 \%$. At the end of the procedure, AuNP are left in CPD where the considerable removal of biological content enables their detection by ensemble characterization techniques, like DLS and ICP-OES.

\subsubsection{Quantification of AuNP retrieved from $S F$.}

A matrix-matched calibration curve showed that it was possible to detect and confidently $\left(\mathrm{r}^{2}=\right.$ 0.9964) measure AuNP by means of ICP-OES once isolated from SF in CPD and then diluted in PBS. Particle quantification is possible without prior acid digestion of the sample. ${ }^{24} \mathrm{~A}$ linear relationship between known amounts of AuNP and light intensity was thus used quantify 
particles isolated from SF aliquots spiked at concentrations between 2.0 and $8.0 \mu \mathrm{g} \mathrm{ml}^{-1}$ (Fig. $5 \mathrm{~A})$ : it was thus calculated that $75.7 \pm 2.1 \%$ of added particles were recovered from $500 \mu \mathrm{l}$ of SF samples spiked at $4.0 \mu \mathrm{g} \mathrm{ml}^{-1}$ (Fig. 5B). More details on the preparation of the calibration curve can be found in Fig. 3 of Supplementary Information. It should be noted that the detected amount of $\mathrm{Au}$ corresponds to particles unassociated with sperm cells. It has been shown that engineered nanoparticles have a variable affinity for the membrane of mammalian sperm cells $^{28,29}$ so that their retrieval is expected to depend on the sperm cell concentration, i.e. the sperm count.

The recovery procedure was tested against other types of engineered nanoparticles where it was found to be less efficient when compared to results obtained from AuNP. The panel included spherical particles $\left(\mathrm{Ag}, \mathrm{SiO}_{2}, \mathrm{TiO}_{2}\right)$ and $\mathrm{Fe}_{2} \mathrm{O}_{3}$ nanorods, but neither their density nor their dimensions appeared definitively associated with the efficacy of the procedure (TEM micrographs of these nanoparticles prior to their retrieval from SF and their retrieval yields as measured by ICP-OES are presented in Fig. 4 of Supplementary Information). It is important to note that the dissolution of materials like $\mathrm{Ag}$ was not investigated. Therefore, we suggest that other types of nanoparticles be tested for dissolution or oxidation phenomena, should the reader decide to apply the proposed protocol.

\subsubsection{Characterisation of AuNP before and after their recovery from SF.}

Direct DLS observation of AuNP in SF is impossible due to its high opacity, high concentration of biological content, and variable viscosity. ${ }^{30}$ Even at high dilution, cells, cellular debris, and soluble biomolecules increase the sample's size dispersity beyond the resolution capacity of light scattering techniques. In fact, the intensity-weighted hydrodynamic size distribution of a AuNP-spiked SF was unusable with a dispersity index (d.i.) = 1.0, while AuNP in $0.1 \mathrm{mM}$ PBS had d.i. $=0.238$. The dispersion of the recovered AuNP presented a distinct peak at $180 \mathrm{~nm}$, but residual cellular debris as well as possible contribution from the buffer contents did not allow for the acquisition of a trustworthy size distribution (d.i. = 0.655). Having said that, the dkcps signal from the recovered particles was significantly stronger compared to the negative sample (SF alone) (Fig. 5C).

The currently proposed procedure was more useful for imaging with scanning electron microscopy. Although AuNP could be detected by back-scatter electron (BSE) imaging in untreated SF (Fig. 6A2) due to their dense core, their morphological observation by traditional secondary electron microscopy detectors was not possible because they were covered by biological material (Fig. 6A3). After the particles' recovery, the sample substrate was evidently 
cleaner with less cellular debris and biomolecules (Fig. 6B1); some AuNP were directly deposited on the substrate while others were lying on rafts of residual organic material, but in both cases their morphology was still discernible (Fig. 6B2, 3).

\subsection{Application of the proposed method on a small patient cohort}

In order to test the applicability of the proposed nanoparticle retrieval method from SF, it was applied to a 18-patient cohort. Its small size could not generate epidemiologically useful information, but it could function as a proof of concept that this newly founded method was in fact clinically applicable. The study was designed in compliance with relevant French legislation, the experiments were anonymised and all patients had given their consent prior to the ex vivo use of biological material and clinical data.

\subsubsection{DLS and ICP-OES data.}

Nine (9) patients with normal sperm count ( $>39 \times 10^{6}$ cells per ejaculate) and 9 with low sperm count (including 2 azoospermic patients) were treated with the proposed method. The obtained results are presented in Table 1 and Fig. 7-9. Average sperm count per ejaculate was the only significantly different clinical trait between the two groups (Table 1). This was reflected on the measured DLS signals from the CPD fractions of patients with normal sperm count which were on average significantly stronger than signals from patients with low sperm count $(p=0.0493)$, probably because of a small amount of residual biological material. A positive correlation $(\mathrm{r}=$ $0.72, p=0.0369$ ) between initial sperm counts and dkcps signals of the CPD fractions for patients with normal sperm count corroborated that residual cellular debris contribute to the DLS signal (Fig. 7A).

Elemental composition of CPD fractions was measured by ICP-OES and was found that Ag, $\mathrm{Al}$, and Ti were either below the method's detection limit or comparable to the blank values. Mean Fe and Si concentrations were in the order of 0.01 and $0.02 \mu \mathrm{g} \mathrm{ml}^{-1}$, respectively, which are below the levels used in animal and in vitro studies that reported particle-related adverse effects (see Introduction for more details). Because the method was tested with different types of nanoparticles and at concentrations $\approx 10 \times$ higher than the detected metal content, it is unknown what fraction of the original content do the measured Fe and Si represent. Differences between the two groups were not significant, but $\mathrm{Si}$ was elevated by $56 \%$ in the low sperm count group (Table $1 \&$ Fig. 7B). In the normal group, Si content of CPD fractions presented a 
moderate, positive correlation with their dkcps signal ( $\mathrm{r}=0.37)$ and, in extent, with the patients' initial sperm count $(r=0.45)$; the same correlations for the low sperm count group were weakly negative, suggesting that the Si content was independent of residual biological noise (Fig. 7C).

\subsubsection{Electron microscopy data.}

CPD fractions from one azoospermic and one patient with normal sperm count were observed under FESEM. The former had a low DLS signal, but presented with the highest amount of Si. In-lens analysis showed little biological material and revealed a small cluster of clearly defined nano-sized objects (Fig. 8B). BSE imaging suggested that it was composed of relatively denser material than its surroundings (Fig. 8A) and is thus safe to assume that it is an agglomerate of exogenous particles.

The sample from the patient with normal sperm count had a moderate DLS signal, but very low amounts of Si and Fe. Inlens analysis showed little biological material, but several micron-sized crystals were observed (Fig. 8D). Contrary to images from the azoospermic patient, the dendritic appearance of particles under BSE imaging suggests that they might have been generated from dissolved metal content (Fig. 8C), as shown elsewhere. ${ }^{31}$ Particulate Si content was not detected by energy-dispersive X-ray (EDX) analyses which could be partially explained by the low atomic number of $\mathrm{Si}$ and the small contrast it should generate on a carbon-coated substrate.Interestingly, EDX did reveal a sub-micrometric, $\mathrm{TiO}_{2}$ particle in the $\mathrm{CPD}$ fraction retrieved from an azoospermic patient (Fig. 9A). Other particle-like objects in the same sample did not contain any significant amounts of metals or Si. In general, most observed particles suggested that they were of biological origin (chemical analyses in Fig. 9A and B) and were thus considered biological residues.

It should be stressed that it is impossible to draw any safe clinical conclusions despite the observed trends in Si content or the detected particles because of the small size of patient cohort. This application was merely a demonstration of the clinical usefulness of the proposed particle isolation protocol from SF. It would require a meta-analysis of a multitude of similar works or a large epidemiological study before any concrete correlations between detected particles and sperm parameters can be stated with relative confidence.

\section{Materials and methods}

Unless otherwise mentioned, the centrifuge used for the experiments was a Heraeus ${ }^{\mathrm{TM}}$ Megafuge $^{\text {TM }} 16$ centrifuge (ThermoFisher Scientific ${ }^{\mathrm{TM}}$ ) equipped with a TX-400 swinging bucket rotor; to minimise non-specific interactions of particles and biological material with the 
containers, we used $2 \mathrm{ml}$ Protein LoBind ${ }^{\mathrm{TM}}$ tubes by Eppendorf®; all chemicals were of $>99 \%$ analytical purity and purchased by Sigma-Aldrich $\odot$, France; the term 'glycerol solution' refers to aqueous solution of $75 \%$ glycerol; tubes were punctured by $22 \mathrm{G} 1^{1 / 2}$ Terumo® needles mounted on $2 \mathrm{ml}$ syringes.

\subsection{Follicular and seminal fluids}

All patients were informed about the purposes of the study and had given their consent before their recruitment, in accordance with relevant French legislation. This study has been approved by the ethics committee of the Saint-Etienne University Hospital. Follicular and seminal fluids were obtained from patients consulting at the Clinic of Assisted Reproduction of the Centre Hospitalier Universitaire in Saint-Etienne, France.

Semen samples were collected by masturbation after 3-5 days of sexual abstinence and sperm parameters were evaluated following the World Health Organization guidelines. Twenty (20) samples with normal sperm parameters were pooled and were used for the development of the ex vivo SF treatment method. For the clinical study, 18 subjects were recruited among whom 7 presented with oligozoospermia (sperm count lower than normal), 2 with azoospermia (nondetectable levels of sperm cells) while 9 had a normal sperm count ( $>39 \times 10^{6}$ cells per ejaculate). Follicular fluid was obtained from 20 patients during oocyte pick-up and was pooled to form the sample used for the development of the ex vivo FF treatment method. For their storage, a 100× penicillin-streptomycin mixture (Biowest SAS, France) was added at a final concentration of $5 \% \mathrm{v} / \mathrm{v}$ in both SF and FF. Between experiments, SF and FF were kept at $-20^{\circ} \mathrm{C}$, protected from light and sealed airtight.

The total protein content of the soluble fraction of SF was measured in the isolated seminal plasma: $500 \mu \mathrm{l}$ of SF was added in $500 \mu \mathrm{l}$ of deionised water and were centrifuged at $(4000 \mathrm{~g}$, $\left.20 \mathrm{~min}, 0^{\circ} \mathrm{C}\right)$. The supernatant volume $(500 \mu \mathrm{l})$ was further diluted in PBS by a factor of $20 \times$ and the Pierce ${ }^{\mathrm{TM}} 660 \mathrm{~nm}$ Protein Assay kit (ThermoFisher Scientific ${ }^{\mathrm{TM}}$ ) was used for protein quantification. In brief, $10 \mu \mathrm{l}$ of the diluted seminal plasma were placed in a 96-well plate, 150 $\mu l$ of the Protein Assay Reagent were added, and the plate was shaken for $60 \mathrm{~s}$, then incubated for 5 min. The sample's absorption at $660 \mathrm{~nm}$ was measured using a microplate reader (Multiskan $^{\mathrm{TM}} \mathrm{GO}$, ThermoFisher Scientific ${ }^{\mathrm{TM}}$ ). Protein concentration was extrapolated by comparison to a standard curve prepared from bovine serum albumin samples. The total protein content of FF was measured following the same procedure, albeit after performing a single $40 \times$ dilution. 


\subsection{AuNP}

Citrate-capped, AuNP dispersed in 0.1 mM PBS were purchased from Sigma-Aldrich, France. The nominal concentration of the stock dispersion and the particles' geometric diameter were $1.9 \times 10^{10}$ particles per $\mathrm{ml}$ and $60 \mathrm{~nm}$, respectively. Their primary size and morphology were observed using a Philips CM 200 TEM and a Supra 55VPтм Carl Zeiss AG FESEM. DLS measurements in liquid media were performed with Zetasizer $^{\mathrm{TM}}$ NanoZS (Malvern Instrumentsk) using $10 \mathrm{~mm}$ path length, disposable poly-methyl methacrylate (PMMA) cuvettes (MC2). Their z-potential in deionised water was measured using a polycarbonate, folded, capillary cell (Malvern Instruments ${ }^{\mathrm{TM}}$ ). The fractions of SFs from the patient cohort were measured in $70 \mu \mathrm{l}$ PMMA optical cuvettes (Brand GMBH \& Co KO, Germany). The equilibrium time was set at $2 \mathrm{~min}$, temperature at $25^{\circ} \mathrm{C}$, refraction index at 1.45 , and measure angle at $173^{\circ}$. The laser beam attenuator and the measurement position were automatically adjusted by the instrument during each run and all measurements were repeated in triplicate.

\subsection{Ex vivo treatment of FF}

\subsubsection{Solubilisation of proteins using CPD.}

The components of CPD were based on existing cell lysis and protein extraction and purification protocols32 while their final concentrations were based on existing proteomic, lipidomic, and cytologic analyses of human SF and FF. Specifically, CPD was prepared by adding the following materials in Milli-Q ${ }^{\circledR}$ water: $50 \mathrm{mM}$ Tris-Base, $0.8 \% \mathrm{v} / \mathrm{v}$ TX100, $0.1 \mathrm{w} / \mathrm{v}$ SDS, $5 \mathrm{M}$ urea, $150 \mathrm{mM} \mathrm{NaCl}, 2 \mathrm{M}$ thiourea, $0.5 \mathrm{w} / \mathrm{v}$ Na-deoxycholate.

Tris base is used to create moderately alkaline ( $\mathrm{pH}$ 7-9) conditions which promote the solubilisation of most proteins. Sodium dodecyl sulfate (SDS) was used because it is an anionic surfactant capable of disrupting both hydrophobic and hydrogen bonds present at hydrophobic regions of denatured clusters and exposed hydrophilic regions of solubilized biomolecules, ${ }^{33}$ respectively. Because SDS disrupts covalent bonds, it also disrupts tertiary protein structures which, in the case of membrane-bound proteins, can lead to cell lysis. Its concentration was such that it did not precipitate, even at low temperatures. Triton X-100 (TX100) -a weaker, nonionic surfactant- was added in the buffer to facilitate the solubilisation of hydrophobic regions present in denatured proteins ${ }^{34}$ and to render membrane-bound proteins miscible, thus causing cell lysis. ${ }^{35}$ It has also been shown that the efficiency of TX100 is increased when used in conjunction with high concentrations of urea and thiourea: ${ }^{36}$ apart from their synergistic action with TX100, these molecules are denaturing agents, capable of disrupting the secondary structure of proteins and the networking of independent peptides by interfering with hydrogen 
bonds. They thus promote the solubilisation of otherwise hydrophobic molecules and prevent protein "gelling", a phenomenon which could sterically confine nanoparticles. The buffer was stored in sealed tubes at $4{ }^{\circ} \mathrm{C}$ between experiments. To test the improvement in protein dispersibility, $1000 \mu \mathrm{FF}$ aliquots were initially centrifuged (1600g, $10 \mathrm{~min}, 4{ }^{\circ} \mathrm{C}$ ) to remove any cells or cellular debris. Then, $333 \mu \mathrm{l}$ of the supernatant were added in $166 \mu \mathrm{l}$ of CPD and incubated at $37{ }^{\circ} \mathrm{C}$ for $20 \mathrm{~min}$. The solution was diafiltrated through a porous membrane with a MWCO at $100 \mathrm{kDa}$ using Amicon® Ultra-0.5 filter devices by centrifugation in fixed-angle centrifuge at $13900 \mathrm{~g}$ for $20 \mathrm{~min}$ at $25^{\circ} \mathrm{C}$. The protein content of the filtrate was then measured using a total protein assay kit as described above. Protein concentration was extrapolated by comparison to a standard curve prepared from bovine serum albumin samples in the presence of CPD components to verify their compatibility with the assay's reagent. The capacity of CPD buffer to disperse the protein content of FF was compared against PBS.

\subsubsection{Light scattering properties of FF spiked with AuNP in the presence of CPD.}

DLS was used to measure the dkcps signal from AuNP at $4.0 \mu \mathrm{g} \mathrm{ml}^{-1}$ in the presence of increasing FF volume fractions before and after their treatment with CPD. FF was first filtered through $0.22 \mu \mathrm{m}$ polyethersulfone (PES) membranes (Merck Millipore ${ }^{\mathrm{TM}}$ ) to remove preexisting particles (dust, cellular debris) that could interfere with the light scattering behavior of AuNP and native protein contents. Then, samples were prepared by mixing $1000 \mu \mathrm{l}$ of filtered FF at various dilutions in PBS (1, 2, 4, 8, 16, 64, and 90\% v/v), a constant volume of stock AuNP dispersion, and $500 \mu \mathrm{l}$ of CPD. The same experiment was performed by substituting CPD with PBS to record the light scattering behavior of the same mixture under physiological conditions.

\subsubsection{Extraction of AuNP from FF in a glycerol solution.}

FF aliquots $(1000 \mu \mathrm{l})$ spiked with AuNP at final concentrations of 1.0, 2.0, and $4.0 \mu \mathrm{g} \mathrm{ml}^{-1}$ were added in $500 \mu \mathrm{l}$ of the as-prepared CPD solution. The contents of the tubes were mixed by inversion and were incubated at $37^{\circ} \mathrm{C}$ for $20 \mathrm{~min}$. Then, $500 \mu \mathrm{l}$ of glycerol solution were slowly deposited at the bottom of the tubes and were centrifuged $\left(4000 \mathrm{~g}, 4 \mathrm{~h}, 4{ }^{\circ} \mathrm{C}\right)$. After centrifugation, the tubes were punctured and the entire FF volume including the region where FF and glycerol had mixed were aspirated. It was empirically found that for as-presented materials and centrifugation parameters, the tubes had to be punctured at $\approx 2.5 \mathrm{~mm}$ beneath the initial FF-glycerol solution interface. The remaining glycerol solution was reconstituted to 1000 
$\mu l$ with the addition of deionised water and was used for particle analyses. The extraction procedure is schematically presented in Fig. 10. Negative controls and blanks for the treatment was FF aliquots that had not been spiked with AuNP and deionised water, respectively.

\subsection{Ex vivo treatment of $S F$ for the recovery of $A u N P$}

In the first step, $500 \mu \mathrm{l}$ of glycerol solution were slowly deposited beneath $500 \mu \mathrm{l}$ of SF aliquots spiked with AuNP at $4.0 \mu \mathrm{g} \mathrm{ml}^{-1}$. With the help of centrifugation $\left(200 \mathrm{~g}, 6 \mathrm{~min}, 0{ }^{\circ} \mathrm{C}\right)$, spermatozoa sedimented in the glycerol department. In the next step, the tubes were punctured at the interface of SF and glycerol and the harvested supernatant was added to $500 \mu \mathrm{l}$ concentrated $\mathrm{H} 2 \mathrm{O} 2(30 \% \mathrm{w} / \mathrm{w})$; the tubes were also sonicated for $30 \mathrm{~s}$ in a cup-horn sonicator at $70 \%$ amplitude (Branson Ultrasonics, USA). In the third step, a stronger centrifugation (4000g, $20 \mathrm{~min}, 0^{\circ} \mathrm{C}$ ) was performed to sediment AuNP and cell debris and remove the soluble fraction of semen in the supernatant plasma $(\approx 950 \mu \mathrm{l})$. Finally, the formed pellet was dispersed with $250 \mu \mathrm{l}$ of a modified version of CPD used for the dispersion of FF (50 mM Tris-Base, 0.1 w/v SDS, $150 \mathrm{mM} \mathrm{NaCl}, 0.5 \mathrm{w} / \mathrm{v}$ Na-deoxycholate, $0.8 \%$ v/v TX100). The tube was vortexed and sonicated until the pellet was completely dispersed and then deionised water was added to a final volume of $1000 \mu \mathrm{l}$. In the final step, $500 \mu \mathrm{l}$ of glycerol solution were slowly deposited at the bottom of the tubes and the samples underwent a final centrifugation $\left(600 \mathrm{~g}, 2 \mathrm{~min}, 0{ }^{\circ} \mathrm{C}\right)$ for the removal of cellular debris. The AuNP-containing supernatant fraction was harvested by puncturing the tubes and was used for subsequent particle analysis. Negative samples were SF aliquots that had not been spiked with AuNP and blanks were measured with deionised water. The same procedure was performed on $370 \mu \mathrm{l}$ of SFs from the patient cohort because of the limited volume of some samples. The entire procedure is schematically presented in Fig. 11.

\subsubsection{Evaluation of removal of biological material from SF.}

The efficiency of the treatment in decreasing the concentration spermatozoa in SF was assessed with the use of Thoma counting chambers. The protein content in the fraction harvested at the end of the procedure was evaluated after replacing the dispersant with deionised water by means of diafiltration. In brief, $500 \mu \mathrm{l}$ of the solution in question were placed in Amicon ${ }^{\circledR}$ Ultra-4 filter devices with MWCO of $3 \mathrm{kDa}$ and centrifuged $\left(4000 \mathrm{~g}, 1 \mathrm{~h}, 25^{\circ} \mathrm{C}\right)$. The concentrate was reconstituted to $500 \mu \mathrm{l}$ with the addition of deionised water and its protein content was measured using a total protein assay kit as described above.

\subsection{ICP-OES measurements}


To explore the elemental composition of particles in SF, FF, and samples from the patient cohort, aliquots from the fractions obtained after the samples' ex vivo treatment were diluted by a factor in PBS for SF-related samples or in deionized water for FF-related samples. Analyses were performed with a Jobin-Yvon Jy138 Ultrace spectrometer at the following wavelengths (nm): $328.068(\mathrm{Ag}), 396.152(\mathrm{Al}), 242.795(\mathrm{Au}), 259.940(\mathrm{Fe}), 251.611(\mathrm{Si})$, and $323.904(\mathrm{Ti})$. For $\mathrm{Au}$, calibration curves were extrapolated by measuring matrix-matched samples spiked with known quantities of stock AuNP dispersion. After subtracting the signal of negative samples, a linear regression between the recorded intensity at $242.795 \mathrm{~nm}$ (y axis) and the spiked mass of AuNP (x axis) was calculated for both SF- and FF-related matrices.

\subsection{Electron microscopy}

Samples $(100 \mu \mathrm{l})$ were triple-washed by centrifugation $\left(4000 \mathrm{~g}, 10 \mathrm{~min}, 25{ }^{\circ} \mathrm{C}\right)$ in deionised water. AuNP extracted from FF were observed by TEM (Jeol 2010, Tokyo, Japan) at $200 \mathrm{kV}$ using 200-mesh Ni-based, carbon coated grids, whereas AuNP recovered from the treatment of SF were observed under FESEM (Supra 55VPTM Carl Zeiss AG). Mica sheets were placed on aluminum stubs and were then coated with a $50 \mathrm{~nm}$ high resolution carbon layer. To immobilise the sheets and minimize charge effects, conductive tape was used to connect the edges of the mica sheet with the rim of the stub. The samples to be analysed were washed (to remove excess glycerol or surfactant molecules) and $\approx 2 \mu 1$ droplets were deposited on the coated surface of the mica sheet where they were left to dry protected from dust. Images were obtained using the angular selective back-scatter detector operated in the 10-20 keV range and with the in-lens secondary electron detector operated at $1 \mathrm{keV}$ at $4 \mathrm{~mm}$ working distance. EDX analyses were performed using two $80 \mathrm{~mm} 2$ silicon drift "X-Max" detectors by Oxford Instruments Ltd on a polished stub of nichrome in order to avoid interference of Si signal from the deposited mica sheet ( $\mathrm{Si}$ was one of the elements analyzed in ICP-OES).

\subsection{Statistical analyses}

Normality of distribution was checked using a Kolmogorov-Smirnov test for patient age, sperm count $\left(10^{6}\right.$ cells per $\left.\mathrm{ml}\right)$, and signal intensities in dkcps from DLS measurements and in A.U. from ICP-OES measurements. Comparisons of mean age, element concentration in SFs, and dkcps between the group of patients with normal sperm count and the group of patients with low sperm count were performed using a Student's t-test. Non-parametric, Spearman's tests were performed to measure the correlation (r) between element concentration in treated SFs, sperm cell count and dkcps, against a statistical significance of $\mathrm{p}=0.05$. 


\section{Conclusions}

The proposed method for the extraction of $60 \mathrm{~nm}$ Au particles from human FF showed that their detection by ICP-OES and measurement of hydrodynamic size distribution by DLS were feasible at concentrations as low as $1.0 \mu \mathrm{g} \mathrm{ml}-1$. Their extraction from samples spiked at 2.0 $\mu \mathrm{g} \mathrm{ml}^{-1}$ was fair at $\approx 55 \%$ and enhanced their observation under TEM. SF demanded a more elaborate treatment for the good $(\approx 76 \%)$ retrieval of AuNP from samples spiked at $4.0 \mu \mathrm{g} \mathrm{ml}^{-1}$. Interestingly, the native biological material of SF was removed so that nanoscale observations of the particle analytes were possible under FESEM. Nevertheless, our data suggest that different types of engineered nanoparticles may variably partition between the soluble fraction of semen and the surface of spermatozoa, which merits additional toxicological investigation. Finally, the proposed treatment for SF was applied on a small patient cohort $(n=18)$. Particulate $\mathrm{Fe}$ - and $\mathrm{Si}$-content were detected as suggested by chemical analyses, although only a TiO2 particle was visualised under electron microscopy. The obtained results were inconclusive regarding mineralogical differences between patients with normal and low sperm count and DLS measurements were variably affected by residual biological noise. Still, it was evident that detailed morphological observations and elemental analyses of the contained metal nanoparticles were possible.

Simple, ex vivo, physical and chemical treatments allowed the quantitative assessment and qualitative characterisation of AuNP in SF and FF at low $\mu \mathrm{g} \mathrm{ml}^{-1}$ levels. Higher particle density is expected to be a favourable factor towards quantitative particle retrieval, so these protocols are more poised for metal and metal oxide nanoparticles, whereas carbon nanostructures might require a different approach. Still, this work provides solid evidence that the clinically-oriented screening of dense, exogenous nanoparticles in complex human biological samples is indeed feasible, but more work will be required for increased sensitivity.

\section{Conflicts of interest}

There are no conflicts to declare.

\section{References}

1 F. A. Cotton, G. Wilkinson, C. A. Murillio and M. Bochmann, Advanced Inorganic Chemistry, Wiley, Chichester, 6th edn, 1999.

2 A. Pietroiusti, L. Campagnolo and B. Fadeel, Small, 2013, 9, 1557-1572.

3 S. H. Swan, E. P. Elkin and L. Fenster, Environ. Health Perspect., 1997, 105, 1228-1232. 
4 H. Levine, N. Jørgensen, A. Martino-Andrade, J. Mendiola, D. Weksler-Derri, I. Mindlis, R. Pinotti and S. H. Swan, Hum. Reprod. Update, 2017, 1-14.

5 L. Braydich-Stolle, S. Hussain, J. J. Schlager and M.-C. Hofmann, Toxicol. Sci., 2005, 88, $412-419$.

6 L. K. Braydich-Stolle, B. Lucas, A. Schrand, R. C. Murdock, T. Lee, J. J. Schlager, S. M. Hussain and M.-C. Hofmann, Toxicol. Sci., 2010, 116, 577-589.

7 N. Asare, C. Instanes, W. J. Sandberg, M. Refsnes, P. Schwarze, M. Kruszewski and G. Brunborg, Toxicology, 2012, 291, 65-72.

8 J. Gromadzka-Ostrowska, K. Dziendzikowska, A. Lankoff, M. Dobrzyńska, C. Instanes, G. Brunborg, A. Gajowik, J. Radzikowska, M. Wojewódzka and M. Kruszewski, Toxicol. Lett., 2012, 214, 251-258.

9 S. Yoshida, K. Hiyoshi, T. Ichinose, H. Takano, S. Oshio, I. Sugawara, K. Takeda and T. Shibamoto, Int. J. Androl., 2009, 32, 337-342.

10 Z. Wang, Z. Chen, Q. Zuo, F. Song, D. Wu, W. Cheng and W. Fan, J. Orthop. Sci., 2013, $18,1020-1026$.

11 Y. Xu, N. Wang, Y. Yu, Y. Li, Y.-B. Li, Y.-B. Yu, X.-Q. Zhou and Z.-W. Sun, PLoS One, 2014, 9, e101572.

12 M. N. Mascarenhas, S. R. Flaxman, T. Boerma, S. Vanderpoel and G. A. Stevens, PLoS Med., 2012, 9, e1001356.

13 H. Langseth, B. Johansen, J. Nesland and K. Kjaerheim, Int. J. Gynecol. Cancer, 2007, 17, 44-49.

14 M. C. Camargo, L. T. Stayner, K. Straif, M. Reina, U. Al-Alem, P. A. Demers and P. J. Landrigan, Environ. Health Perspect., 2011, 119, 1211.

15 R. Stelzer and R. J. Hutz, J. Reprod. Dev., 2009, 55, 685-690.

16 L. Preaubert, B. Courbiere, V. Achard, V. Tassistro, F. Greco, T. Orsiere, J.-Y. Bottero, J. Rose, M. Auffan and J. Perrin, Nanotoxicology, 2016, 10, 111-117.

17 R. Tassinari, F. Cubadda, G. Moracci, F. Aureli, M. D’Amato, M. Valeri, B. De Berardis, A. Raggi, A. Mantovani, D. Passeri, et al., Nanotoxicology, 2014, 8, 654-662.

18 J. K. Larson, M. J. Carvan IiI, J. G. Teeguarden, G. Watanabe, K. Taya, E. Krystofiak and R. J. Hutz, Nanotoxicology, 2014, 8, 856-866.

19 D. Bitounis, J. Pourchez, V. Forest, D. Boudard, M. Cottier and J.-P. Klein, Biomaterials, 2016, 76, 302-312.

20 A. International, Standard Practice for Retrieval and Analysis of Medical Devices, and Associated Tissues and Fluids, Astm intrenational technical report, 2013. 
21 I. S. Organization, Wear of implant materials - Polymer and metal wear partices - Isolation and characterization, ISO Standard 17853:2011, 2011.

22 F. Von der Kammer, P. L. Ferguson, P. A. Holden, A. Masion, K. R. Rogers, S. J. Klaine, A. A. Koelmans, N. Horne and J. M. Unrine, Environ. Toxicol. Chem., 2012, 31, 32-49.

23 E. Cao, Y. Chen, Z. Cui and P. R. Foster, Biotechnol. Bioeng., 2003, 82, 684-690.

24 H. E. Pace, N. J. Rogers, C. Jarolimek, V. A. Coleman, C. P. Higgins and J. F. Ranville, Anal. Chem., 2011, 83, 9361-9369.

25 M. K. Siu and C. Y. Cheng, Adv. Exp. Med. Biol., 2012, 763, 186.

26 N. Fernández-Iglesias and J. Bettmer, Nanoscale, 2015, 7, 14324-14331.

27 C. Mylonas and D. Kouretas, In Vivo, 1998, 13, 295-309.

28 U. Taylor, A. Barchanski, S. Petersen, W. A. Kues, U. Baulain, L. Gamrad, L. Sajti, S. Barcikowski and D. Rath, Nanotoxicology, 2014, 8, 118-127.

29 S. Ben-David Makhluf, R. Qasem, S. Rubinstein, A. Gedanken and H. Breitbart, Langmuir, 2006, 22, 9480-9482.

30 D. H. Owen and D. F. Katz, J. Androl., 2005, 26, 459-469.

31 S. Bakhti, S. Biswas, C. Hubert, S. Reynaud, F. Vocanson and N. Destouches, J. Phys. Chem. C, 2014, 118, 7494-7500.

32 M. Peach, N. Marsh and D. J. MacPhee, Protein Electrophoresis: Methods and Protocols, 2012, pp. 37-47.

33 T. Rabilloud, S. Luche, V. Santoni and M. Chevallet, Plant proteomics: methods and protocols, 2007, pp. 111-119.

34 B. Herbert, Electrophoresis, 1999, 20, 660-663.

35 J. B. Harford and J. S. Bonifacino, Current Protocols in Cell Biology, John Wiley \& Sons, New Jersey, 2010.

36 S. Luche, V. Santoni and T. Rabilloud, Proteomics, 2003, 3, 249-253. 


\section{Tables}

Table 1 - Comparisons of clinical and analytical data between patients with normal and low sperm count

\begin{tabular}{|c|c|c|c|c|c|c|c|}
\hline & $\begin{array}{c}\text { Age } \\
\text { (years } \pm \text { S.D) }\end{array}$ & $\begin{array}{c}\text { Patients } \\
\text { w. } \\
\text { offsprings } \\
(\%)\end{array}$ & $\begin{array}{c}\text { Tobacco } \\
\text { smokers } \\
(\%)\end{array}$ & $\begin{array}{c}10^{6} \text { cells } \\
\text { per } \\
\text { ejaculate }\end{array}$ & $\begin{array}{l}\text { dkcps } \\
\text { (S.D.) }\end{array}$ & $\begin{array}{c}\text { [Si] } \\
\mu \mathrm{g} \mathrm{ml}^{-1} \\
\text { (S.D.) }\end{array}$ & $\begin{array}{c}{[\mathrm{Fe}]} \\
\mu \mathrm{g} \mathrm{ml}^{-1} \\
\text { (S.D.) }\end{array}$ \\
\hline $\begin{array}{l}\text { Normal } \\
\text { sperm count } \\
(\mathrm{n}=9)\end{array}$ & 36.9 & $56 \%$ & $56 \%$ & 285.2 & $\begin{array}{c}6309 \\
( \pm 5691)\end{array}$ & $\begin{array}{l}0.0155 \\
(0.093)\end{array}$ & $\begin{array}{c}0.012 \\
(0.011)\end{array}$ \\
\hline $\begin{array}{l}\text { Low sperm } \\
\text { count }(\mathrm{n}=9)\end{array}$ & 36.2 & $22 \%$ & $44 \%$ & 11.4 & $\begin{array}{c}2094 \\
( \pm 1711)\end{array}$ & $\begin{array}{l}0.0242 \\
(0.152)\end{array}$ & $\begin{array}{c}0.011 \\
(0.012)\end{array}$ \\
\hline$p$ value & 0.84 & 0.32 & 0.97 & 0.0005 & 0.0493 & 0.16 & 0.84 \\
\hline
\end{tabular}




\section{Figure captions}

Fig. 1 (A) FESEM imaging of a AuNP cluster. Scale bar at $100 \mathrm{~nm}$. Overlaid in white is their intensity-weighted hydrodynamic size distribution at $4.0 \mu \mathrm{g} \mathrm{ml}-1$ in deionised water as measured by DLS. (B) Pooled SF (left) and FF at room temperature.

Fig. 2 (A) Light scattering intensity (dkcps) of AuNP $\left(4.0 \mu \mathrm{g} \mathrm{ml}^{-1}\right)$ in the presence of increasing FF volume ratios. The effect of CPD is traced by the open circles: dkcps signal in the presence of surfactants is initially decreasing, contrary to what is observed when CPD is replaced by PBS (closed circles). Error bars represent sample standard deviations (S.D.) $(\mathrm{n}=3)$ and were omitted if smaller than the circles' size. (B) The increasing volume ratio of FF in a AuNP dispersion of $4.0 \mu \mathrm{g} \mathrm{ml}^{-1}$ causes gradual dissipation of the nanoparticle peak and simultaneous emergence of a smaller peak due to the elevated biomolecular content.

Fig. 3 (A) DLS measurements of dkcps-weighted hydrodynamic size distributions of FF (dashed line), AuNP at $4.0 \mu \mathrm{g} \mathrm{ml}^{-1}$ in $0.1 \mathrm{mM}$ PBS (black line) or in FF (dotted line), and extracted AuNP from FF (thicker grey line). (B) One-way ANOVA test showed that dkcps signals of the negative sample and of AuNP extracted from FF differed significantly $(\mathrm{p}<$ 0.0001); post-hoc multiple comparisons between successive groups also revealed significant differences $(* * * * p<0.0001)$. (C) Linear regression with $99 \%$ confidence bands between known amounts of AuNP in matrix-matched glycerol-based samples and light intensity obtained during ICP-OES measurements (the signal of negative samples has been subtracted from the spiked samples' signals). Vertical lines indicate the region of usability for the calibration curve. Error bars represent S.D. $(n=3)$.

Fig. 4 TEM pictures of (A) untreated FF without AuNP, (B) treated FF without AuNP, and (C) AuNP extracted from FF. Scale bars of A and C at $500 \mathrm{~nm}$; scale bar of C at $2 \mu \mathrm{m}$.

Fig. 5 (A) Linear regression with 99\% confidence bands between known amounts of AuNP in matrix-matched CPD-based samples and light intensity obtained during ICP-OES measurements. Vertical lines indicate the region of usability for the calibration curve. (B) DLS measurements: Student's t-test showed that the dkcps signal of AuNP recovered from SF spiked at $4.0 \mu \mathrm{g} \mathrm{ml}^{-1}$ was significantly stronger than the signal from negative samples (SF alone) ${ }^{* *} \mathrm{p}$ $<0.01)$. Error bars represent S.D. $(\mathrm{n}=3)$. 
Fig. 6 FESEM imaging of SF spiked with AuNP at $4.0 \mu \mathrm{g} \mathrm{ml}^{-1}$ before (A1-A3) and after (B1B3) its treatment with the proposed method. (A1, B1) Low-magnification, secondary electron imaging of the general specimen: the amount of sperm cells is evidently decreased in the treated sample. (A2, B2) BSE imaging for the detection of AuNP due to their dense metal core: particles are detectable both before and after the treatment. (A3, B3) In-lens detector imaging for the high-resolution analysis of nano-sized morphological characteristics: without treatment AuNP are completely covered by biological material, while easily observable in the treated sample (even when deposited on rafts of residual organic material as shown in the B3 inset). Scale bars: A1, B1: $10 \mu \mathrm{m}$; A2: $1 \mu \mathrm{m}$; B2: $2 \mu \mathrm{m}$; A3, A3 inset: $200 \mathrm{~nm}, 100 \mathrm{~nm}$; B3: $10 \mu \mathrm{m}$.

Fig. 7 DLS and ICP-OES analyses of CPD fractions retrieved after the treatment of SFs with the currently proposed method. dkcps signals (A) and Si content in $\mu \mathrm{g} \mathrm{ml}^{-1}$ (B) from the CPD fractions of patients with normal sperm parameters (right segments of $\mathrm{x}$ axes, closed circles) and oligospermic or azoospermic patients (left segments of $\mathrm{x}$ axes, open circles). (C) Si content plotted against dkcps signal for both groups. Red coloured symbols mark the patients chosen for FESEM analyses; error bars represent S.D. for $\mathrm{n}=3$ and have been omitted if smaller than the symbol's size.

Fig. 8 (A) BSE and (B) in-lens detector imaging of semen from an azoospermic patient treated with the presented method. White arrows show cluster of nanoparticles of unknown origin. (C) BSE and (D) in-lens detector imaging of semen from a patient with normal sperm parameters. White arrow and circle show some nano-sized and micron-sized crystalline formation, respectively. Scale bars: A, $5 \mu \mathrm{m}$; B, $1 \mu \mathrm{m}$; C, D, $10 \mu \mathrm{m}$.

Fig. 9 EDX analyses of CPD fractions retrieved from the azoospermic patient. (A) A TiO2 submicrometric particle was identified in the semen of an azoospermic patient (spectrum 34, top inset) (B) Other debris in the same sample had an elemental profile that suggested a biological origin. Ni signal in all spectra is generated from the employed equipment. Scale bars: A, $1 \mu \mathrm{m}$; $\mathrm{B}, 5 \mu \mathrm{m}$.

Fig. 10 Schematic for the extraction procedure of AuNP from FF. The addition of CPD deagglomerates clusters of protein molecules and possibly facilitates the extraction of AuNP by 
centrifugation in a glycerol-based cushion. Inset shows a photograph of the tube at the end of the procedure.

Fig. 11 Schematic for the retrieval of AuNP from SF. Optical microscopy was performed at $40 \times$ magnification. 
Figure 1

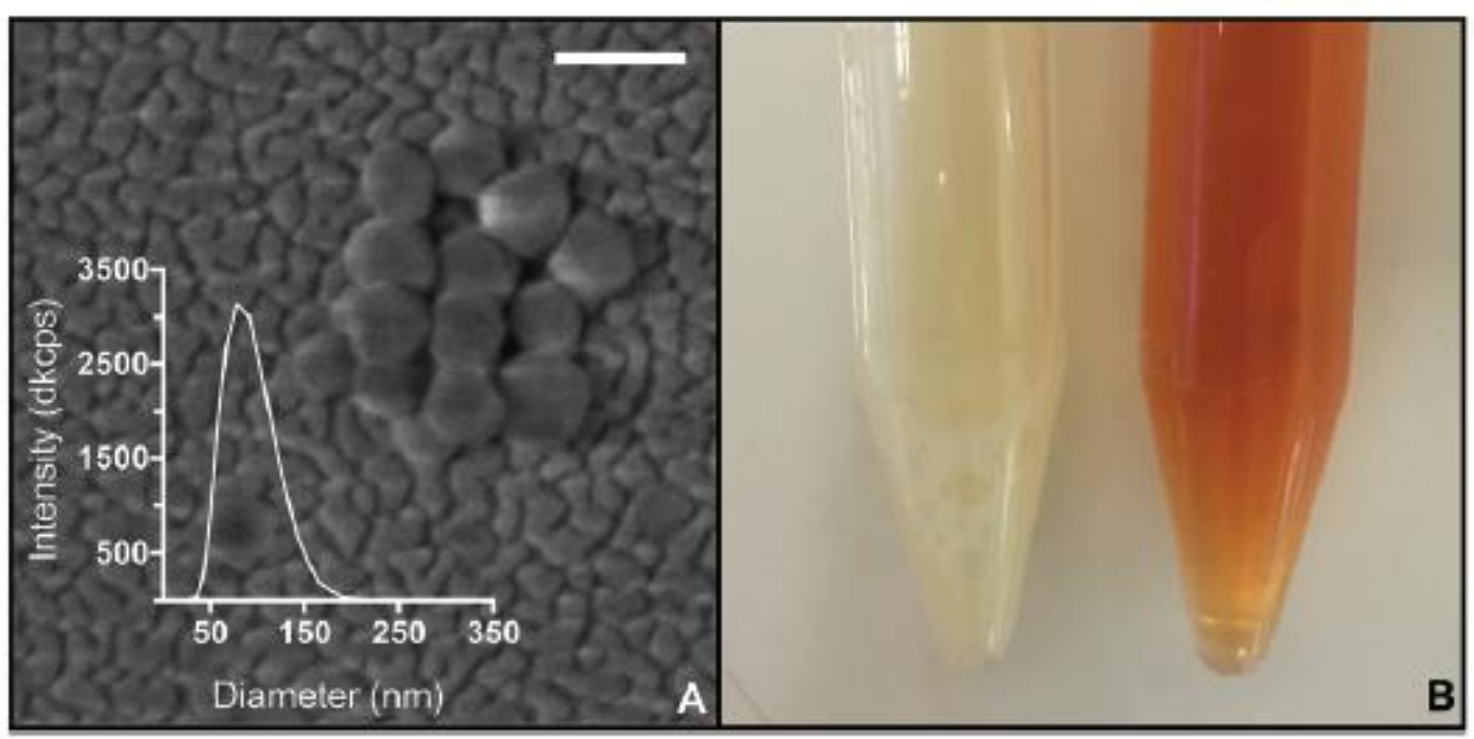

Figure 2

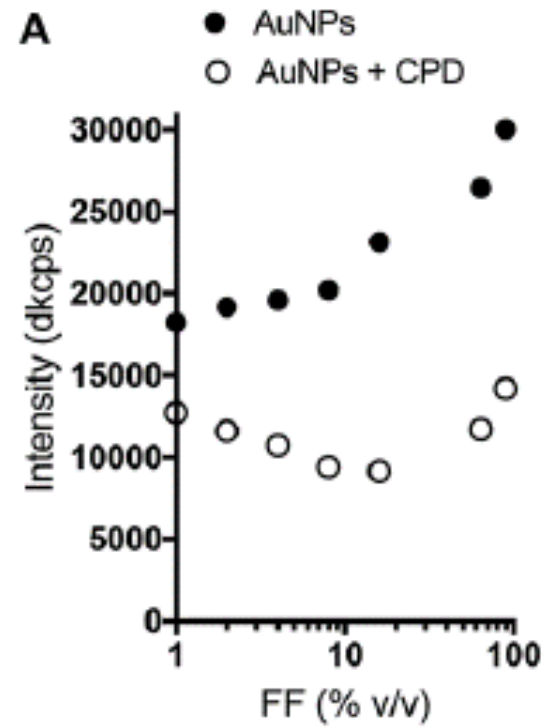

B

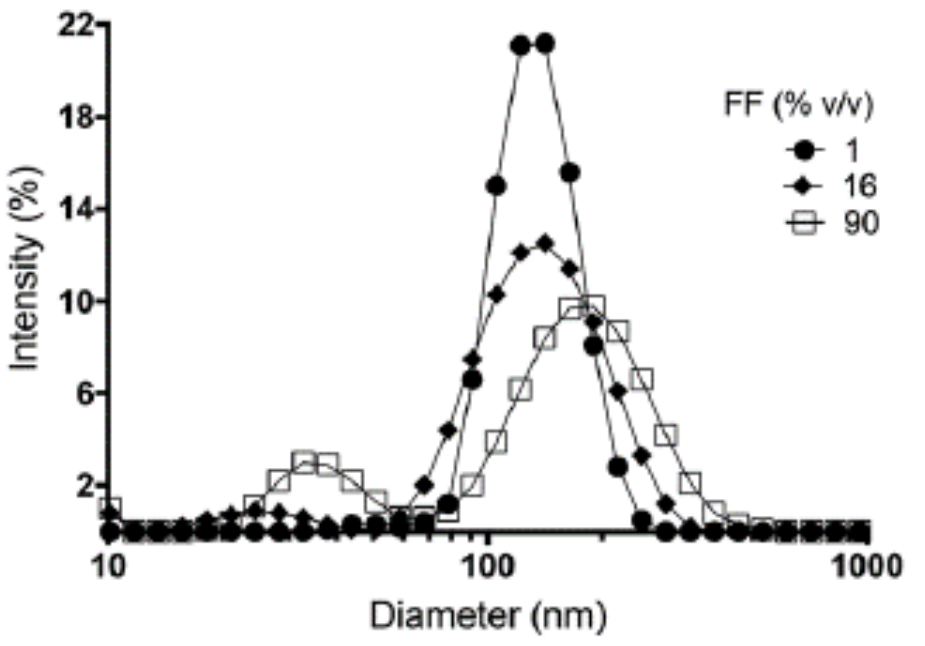




\section{Figure 3}

A

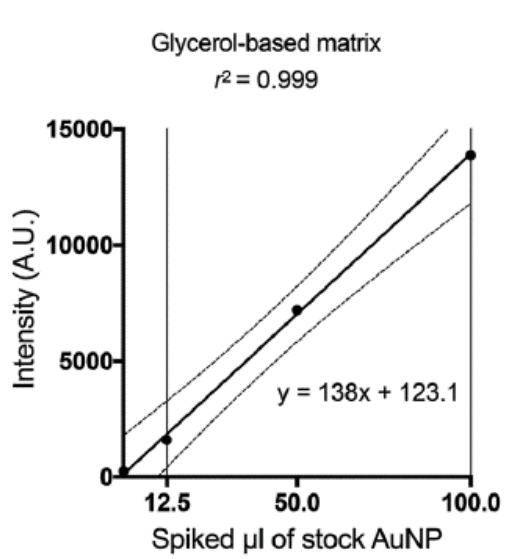

B

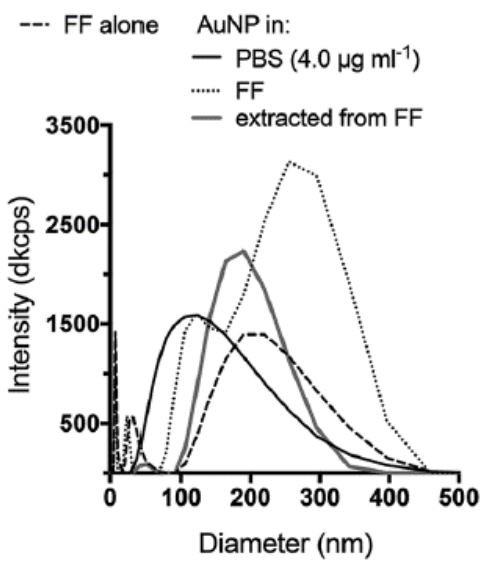

C

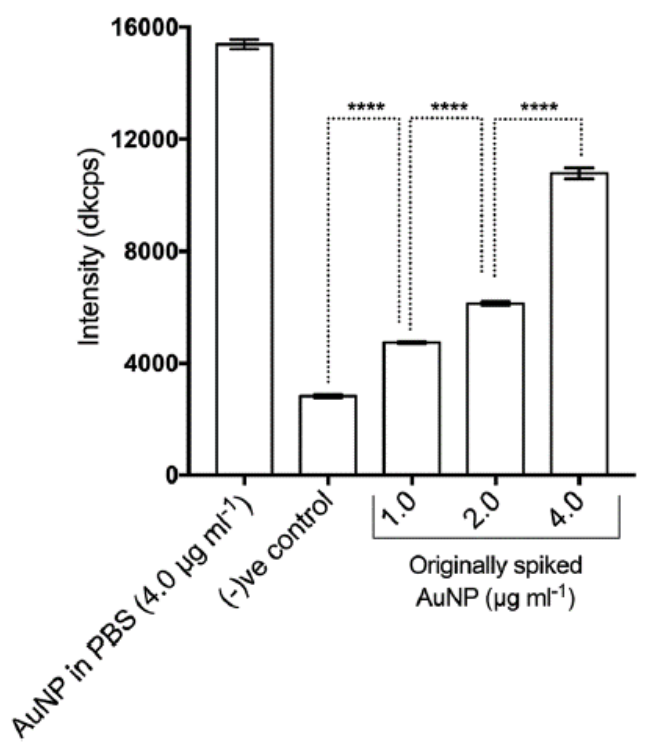

\section{Figure 4}

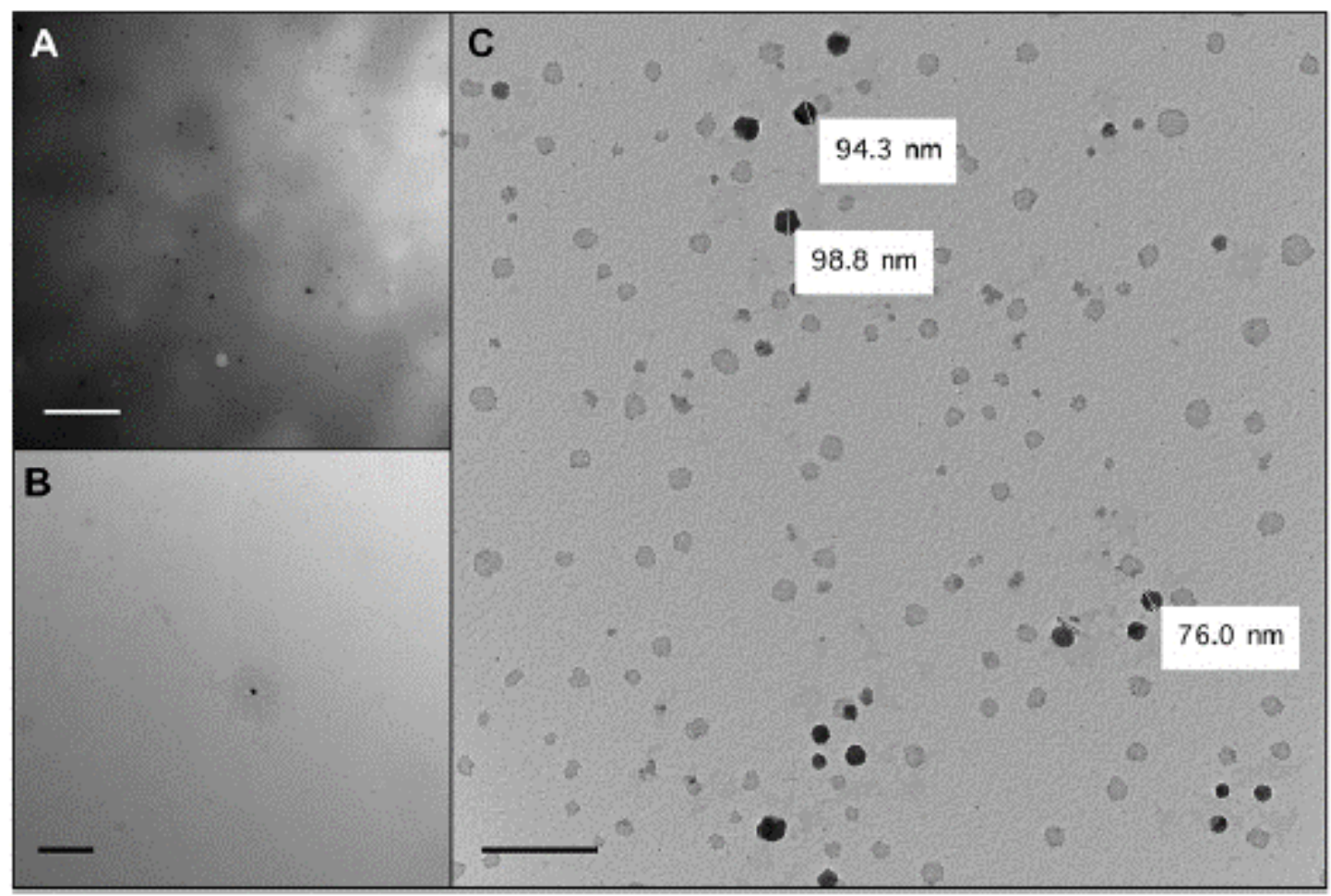


Figure 5

A

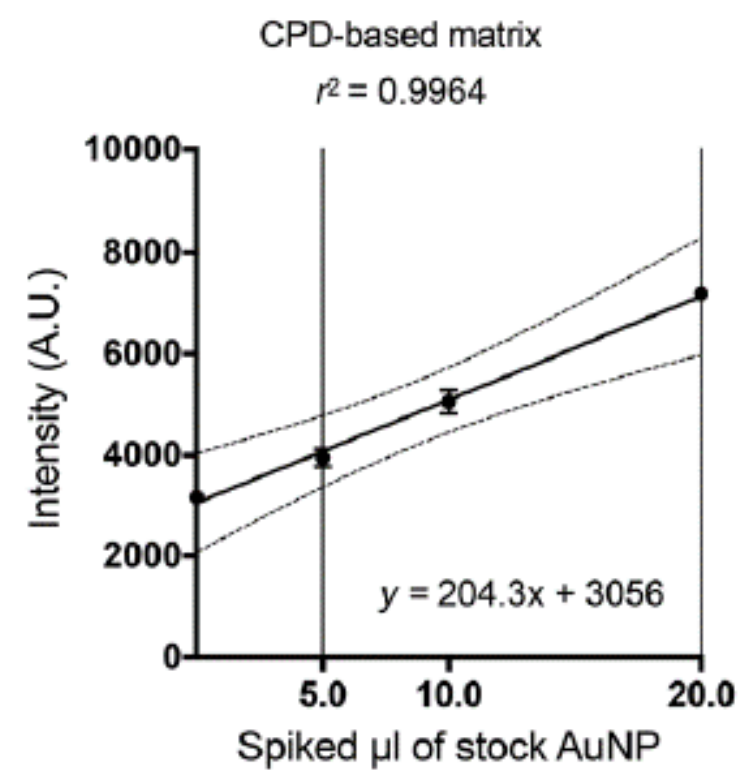

B

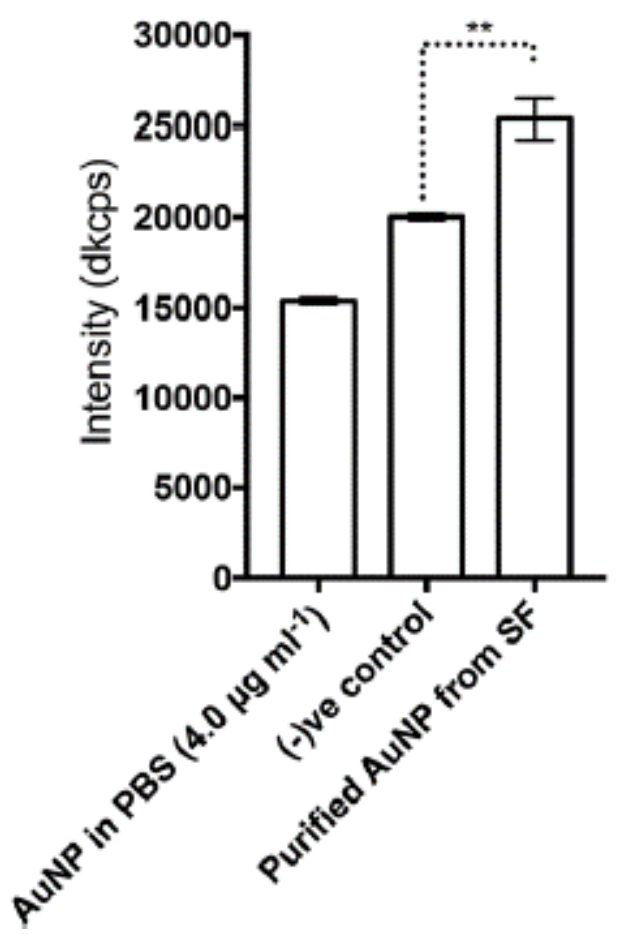

Figure 6
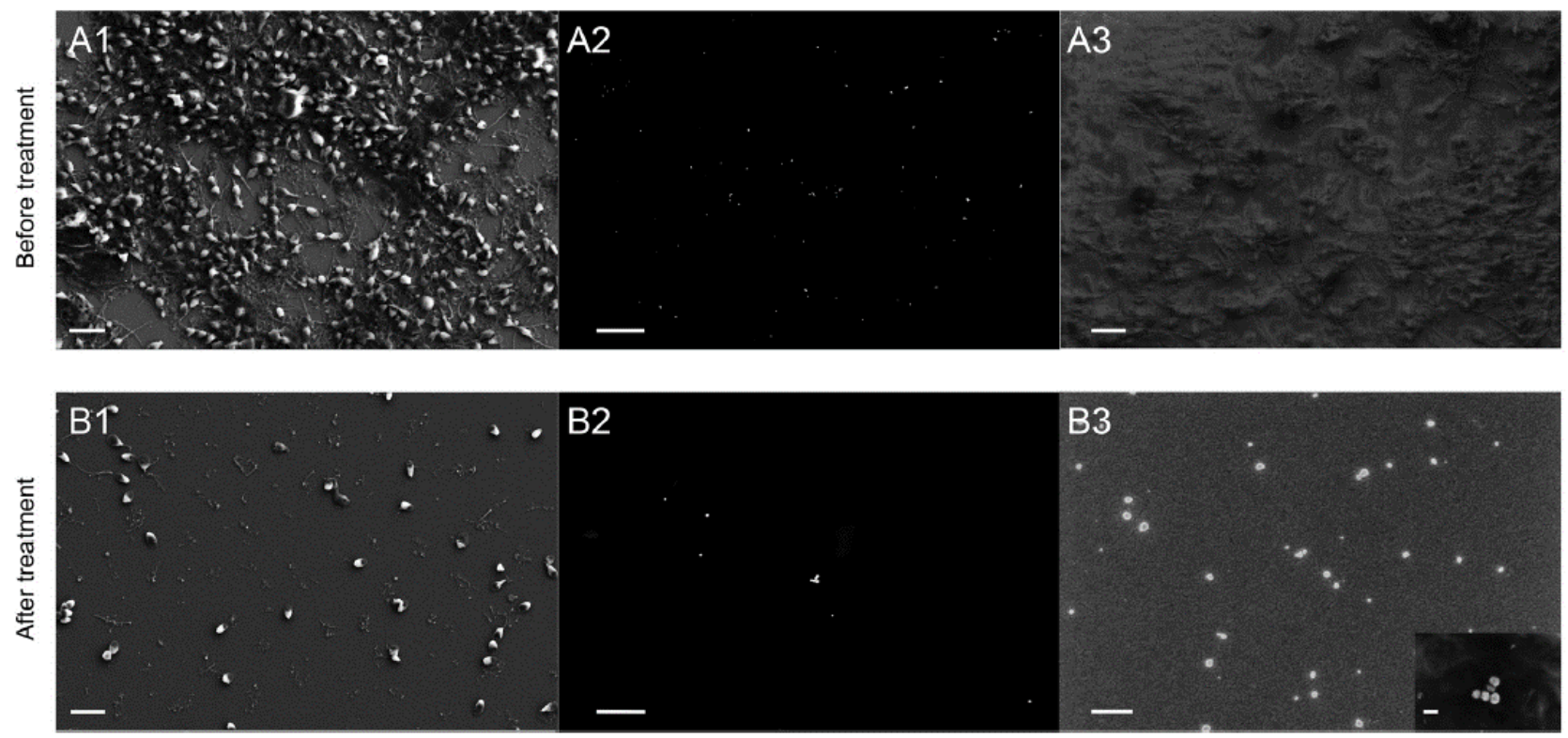


\section{Figure 7}
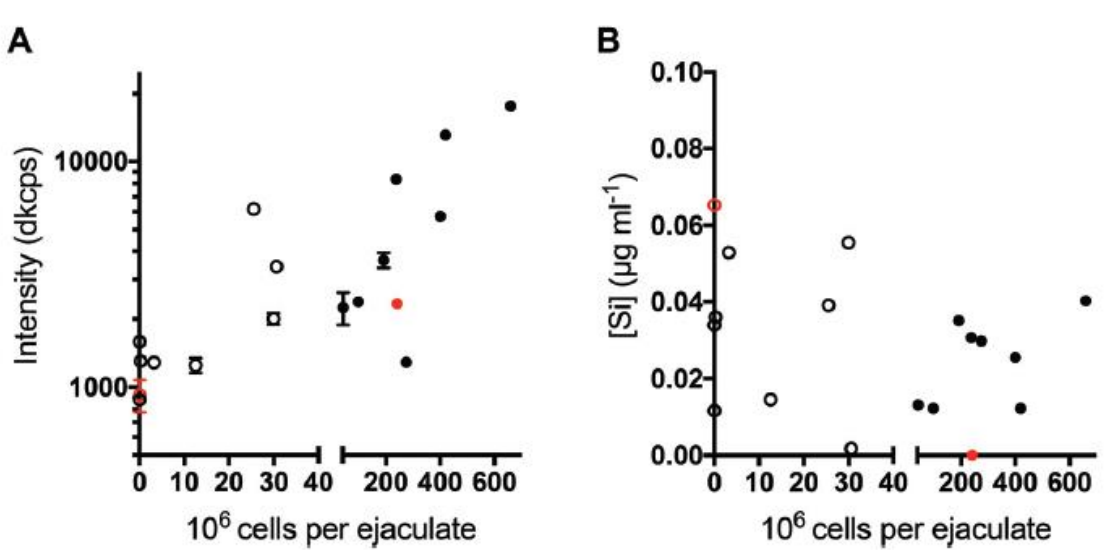

- normal sperm count

- low sperm count

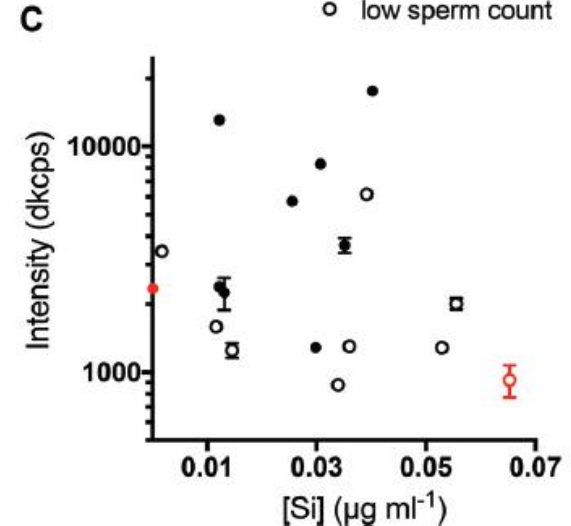

Figure 8

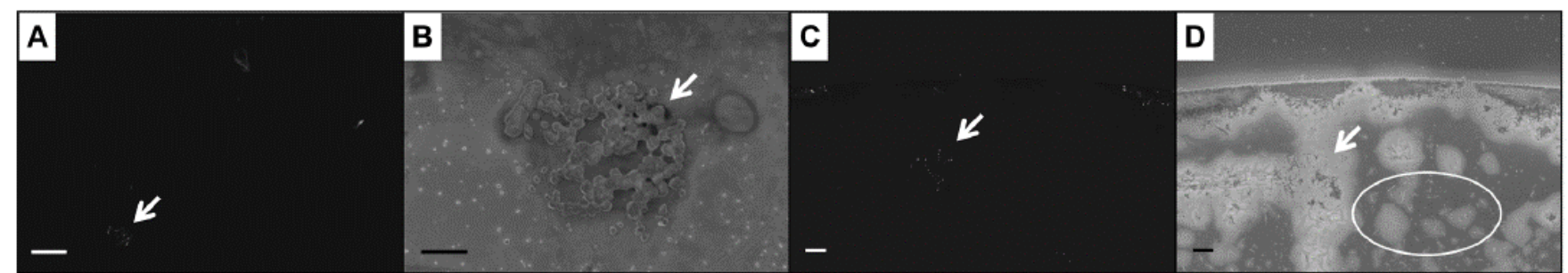

Figure 9
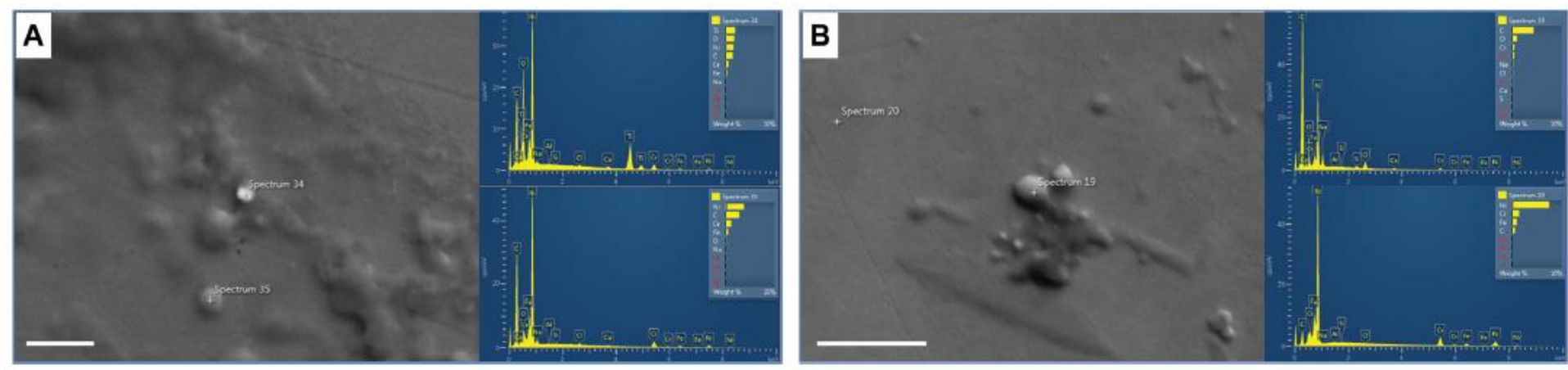


\section{Figure 10}

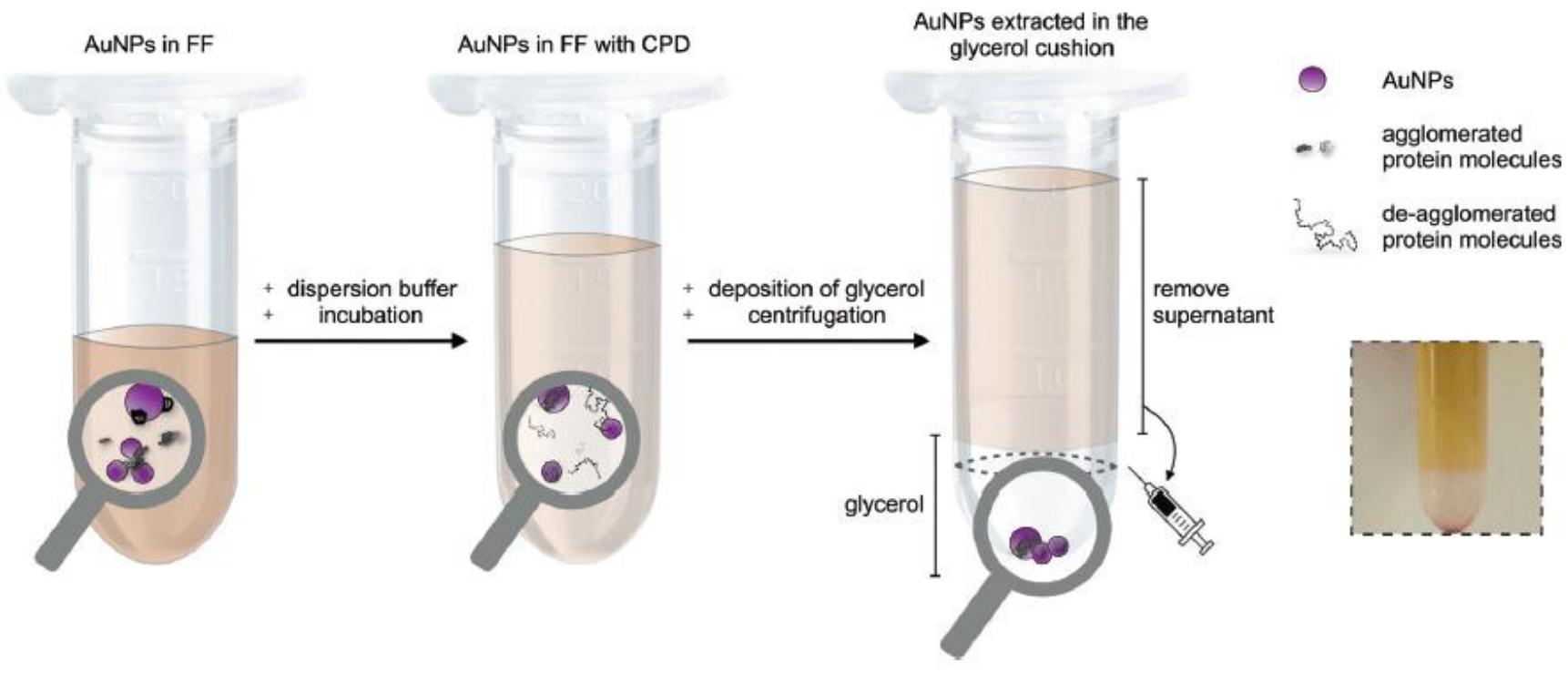

Figure 11

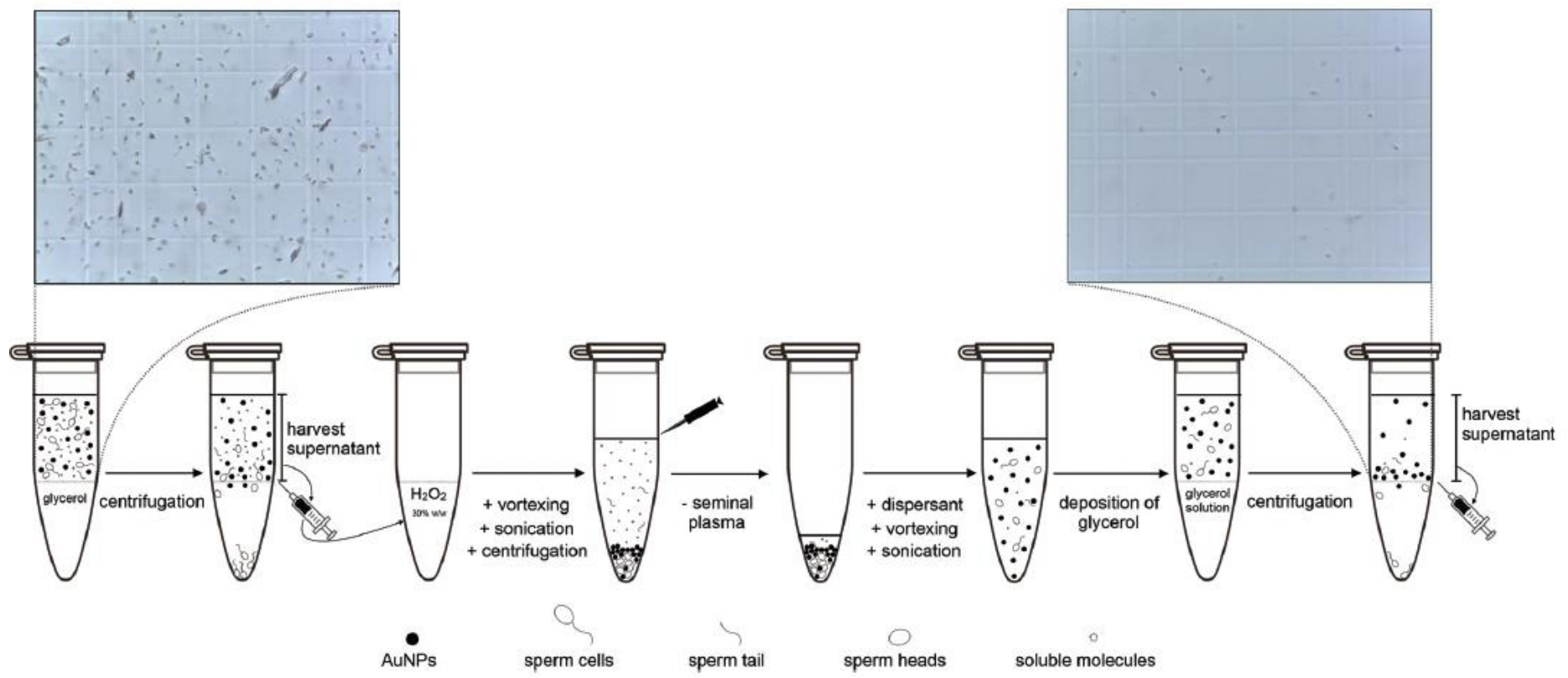




\section{SUPPLEMENTARY INFORMATION}
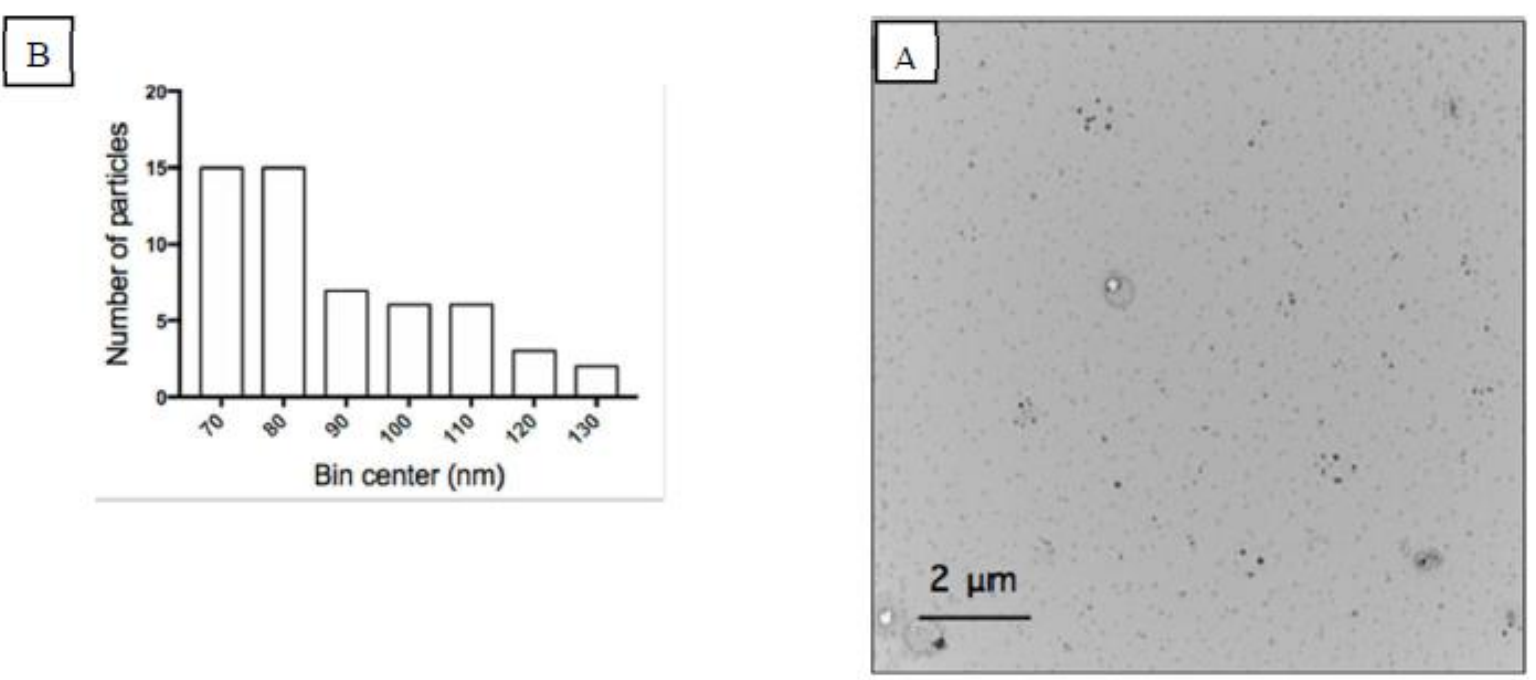

Fig. 1 (A) Transmission electron microscopy (TEM) micrograph of gold nanoparticles (AuNP) extracted from follicular fluid (FF) as presented in the main text, but in larger format. (B) TEM micrograph of the same sample at lower magnification. (C) Frequency distribution of AuNP diameters after their extraction form FF as measured with Image $(n=55)$.
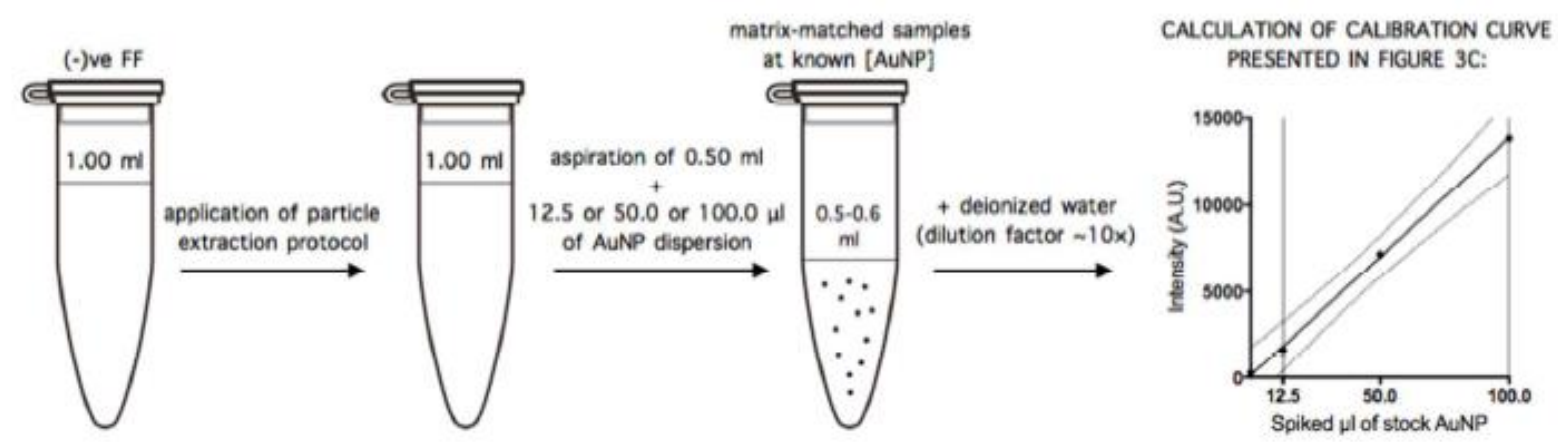

Fig. 2 Preparation of calibration curve for the quantification by means of inductively coupled plasma optical emission spectroscopy (ICP-OES) of AuNP extracted from FF: initially, undiluted FF aliquots $(1.00 \mathrm{ml})$ were treated according to the particle extraction protocol as presented in the main text; then, known quantities of AuNP were added in $0.50 \mathrm{ml}$ of the prepared samples. These were finally diluted in deionized water before measuring their light intensity at $242.795 \mathrm{~nm}$ by ICP-OES. Due to the initial FF aliquots volume $(1.00 \mathrm{ml})$, the volume used for ICP-OES measurements $(0.50 \mathrm{ml})$, and the nominal concentration of the stock AuNP dispersion ( $40 \mu \mathrm{g} \mathrm{ml}-1)$, the calculated calibration curve can be used for quantifying AuNP in FF in the range of 1-8 $\mu \mathrm{g}$ ml-1. All measurements were performed in triplicate and error bars represent sample standard deviation (S.D.). 


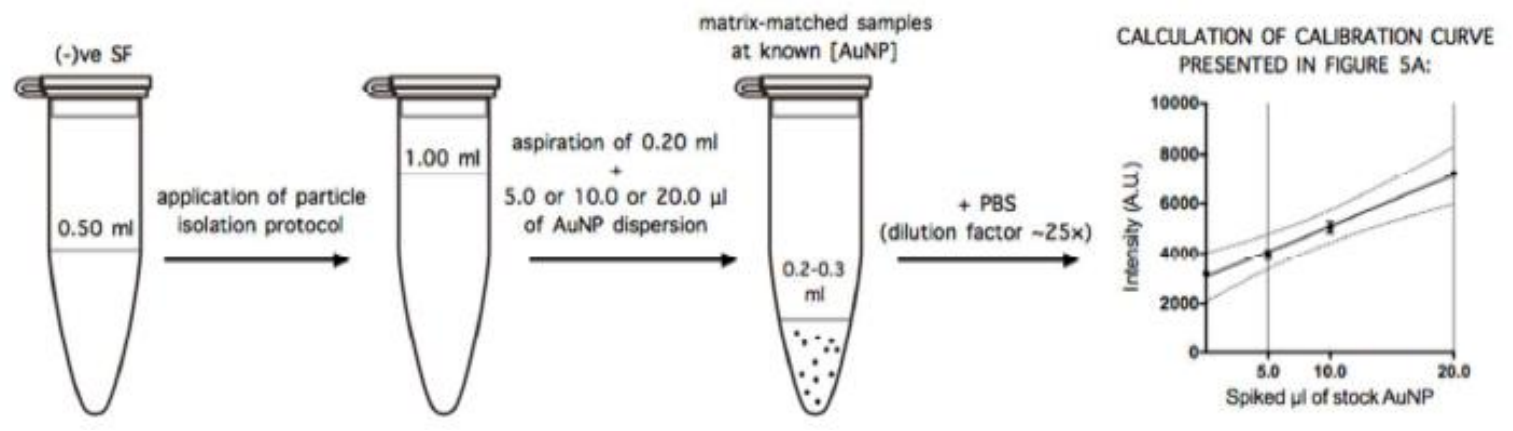

Fig. 3 Preparation of calibration curve for the quantification by means of ICP-OES of AuNP retrieved from seminal fluid $(\mathrm{SF})$ : initially, undiluted $\mathrm{SF}$ aliquots $(0.50 \mathrm{ml})$ were treated according to the particle isolation protocol as presented in the main text; then, known quantities of AuNP were added in $0.20 \mathrm{ml}$ of the prepared samples. These were finally diluted in PBS before measuring their light intensity at $242.795 \mathrm{~nm}$ by ICP-OES. Due to the initial SF aliquots volume $(0.50 \mathrm{ml})$, the volume used for $\mathrm{Au}$ quantification $(0.20 \mathrm{ml})$, and the nominal concentration of the stock AuNP dispersion $\left(\sim 40 \mu \mathrm{g} \mathrm{ml}^{-1}\right)$, the calculated calibration curve can be used for quantifying AuNP in SF in the range of 2-8 $\mu \mathrm{g} \mathrm{ml}^{-1}$. All measurements were performed in triplicate and error bars represent sample standard deviation (S.D.).
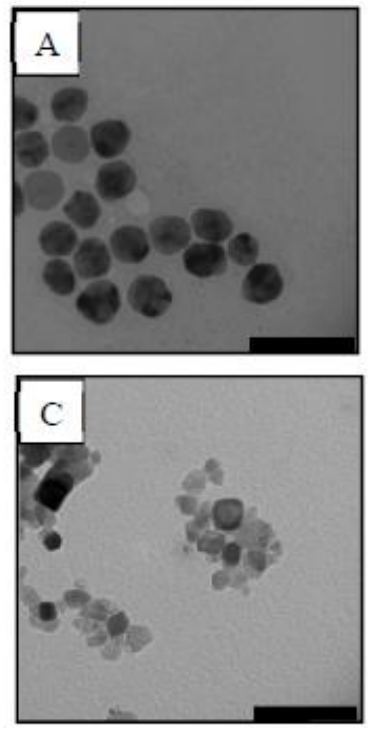
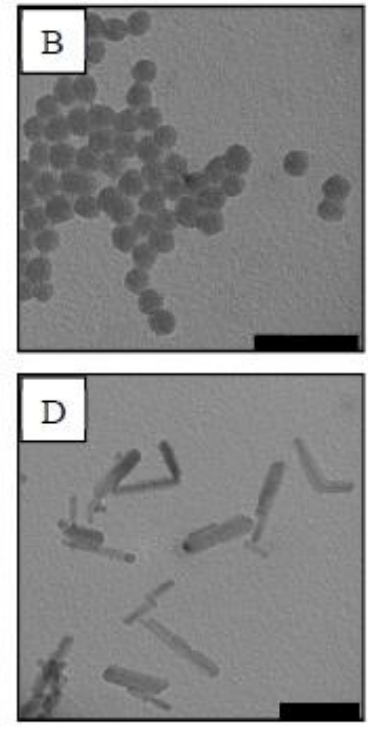
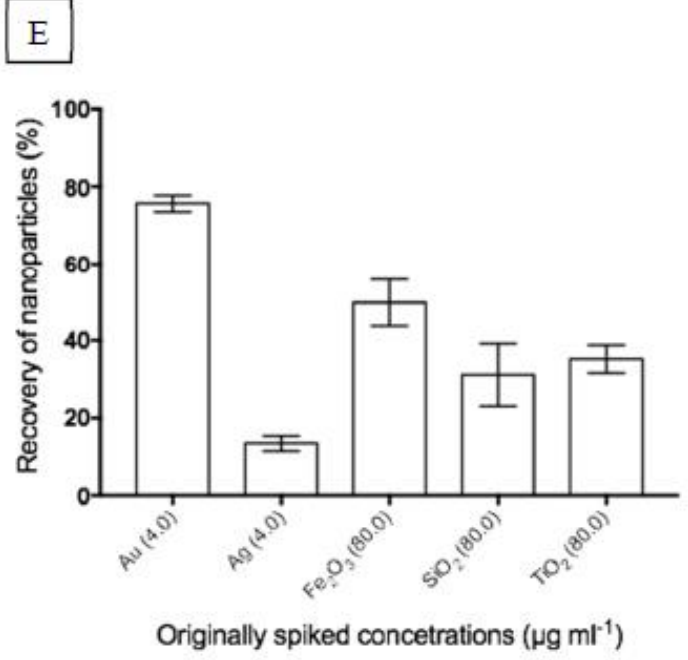

Originally spiked concetrations $\left(\mu \mathrm{g} \mathrm{ml}^{-1}\right)$

Fig. 4 TEM micrographs of engineered nanoparticles tested with the proposed particle isolation method for SF: (A) Ag, (B) $\mathrm{SiO}_{2}$, (C) $\mathrm{TiO}_{2}$, and (D) $\mathrm{Fe}_{2} \mathrm{O}_{3}$. All scale bars are at 100nm. (E) The recovery yields for the above mentioned nanoparticles from SF were measured by ICP-OES. Their quantification was performed similarly to the process followed for AuNP, i.e., with processed SF aliquots which were then spiked with known quantities of each type of material. All measurements were performed in triplicate and error bars represent S.D. 